\title{
Progress Toward Efficient Laminar Flow Analysis and Design
}

\author{
Richard L. Campbell ${ }^{1}$ \\ NASA Langley Research Center, Hampton VA, 23681 \\ Matthew L. Campbell ${ }^{2}$ \\ Independent Consultant, Newport News VA, 23606 \\ Thomas Streit ${ }^{3}$ \\ DLR, Institut für Aerodynamik und Strömungstechnik, 38108, Braunschweig, Germany
}

\begin{abstract}
A multi-fidelity system of computer codes for the analysis and design of vehicles having extensive areas of laminar flow is under development at the NASA Langley Research Center. The overall approach consists of the loose coupling of a flow solver, a transition prediction method and a design module using shell scripts, along with interface modules to prepare the input for each method. This approach allows the user to select the flow solver and transition prediction module, as well as run mode for each code, based on the fidelity most compatible with the problem and available resources. The design module can be any method that designs to a specified target pressure distribution. In addition to the interface modules, two new components have been developed: 1) an efficient, empirical transition prediction module (MATTC) that provides n-factor growth distributions without requiring boundary layer information; and 2) an automated target pressure generation code (ATPG) that develops a target pressure distribution that meets a variety of flow and geometry constraints. The ATPG code also includes empirical estimates of several drag components to allow the optimization of the target pressure distribution. The current system has been developed for the design of subsonic and transonic airfoils and wings, but may be extendable to other speed ranges and components. Several analysis and design examples are included to demonstrate the current capabilities of the system.
\end{abstract}

\section{Nomenclature}

$\begin{array}{ll}\mathrm{C}_{\mathrm{p}} & =\text { pressure coefficient } \\ \mathrm{C}_{\mathrm{pa}} & =\text { pressure coefficient at the flow attachment line on an airfoil } \\ \mathrm{C}_{\mathrm{pm}} & =\text { minimum pressure coefficient on the airfoil upper surface } \\ \mathrm{C}_{\mathrm{pte}} & =\text { pressure coefficient at the airfoil trailing edge } \\ \mathrm{C}_{\mathrm{p}} & =\text { pressure coefficient slope } \\ \mathrm{C} & =\text { airfoil chord } \\ \mathrm{C}_{\mathrm{d}} & =\text { section drag coefficient (CD in plots) } \\ \mathrm{C}_{\mathrm{df}} & =\text { section friction drag coefficient } \\ \mathrm{C}_{\mathrm{dp}} & =\text { section pressure drag coefficient } \\ \mathrm{C}_{\mathrm{dw}} & =\text { section wave drag coefficient } \\ \mathrm{C}_{\mathrm{l}} & =\text { section lift coefficient (CL in plots) } \\ \mathrm{K} & =\text { Korn parameter } \\ \mathrm{k} & =\text { airfoil surface curvature at the shock location } \\ \mathrm{M} & =\text { local Mach number } \\ \mathrm{M}_{\mathrm{n}} & =\text { component of free-stream Mach number normal to wing leading edge } \\ \mathrm{M}_{1} & =\text { Mach number at the shock location }\end{array}$

\footnotetext{
${ }^{1}$ Senior Research Engineer, Configuration Aerodynamics Branch, MS 499. AIAA Associate Fellow.

${ }^{2}$ Independent Consultant, Newport News VA, 23606, smurph@vt.edu

${ }^{3}$ Research Scientist, DLR Braunschweig, Lilienthalplatz 7, 38108 Braunschweig, th.streit@dlr.de
}

1

American Institute of Aeronautics and Astronautics 


$\begin{array}{ll}\mathrm{M}_{\infty} & =\text { free-stream Mach number } \\ \mathrm{N} & =\mathrm{n} \text {-factor } \\ \mathrm{NFE} & =\mathrm{n} \text {-factor exponent used in CDISC NLFCP constraint } \\ \mathrm{N}_{\mathrm{cf}} & =\text { crossflow n-factor } \\ \mathrm{N}_{\mathrm{tr}} & =\mathrm{n} \text {-factor at the desired transition location (critical n-factor) } \\ \mathrm{N}_{\mathrm{ts}} & =\text { Tollmien-Schlichting n-factor } \\ \mathrm{R}_{\mathrm{C}} & =\text { Reynolds number based on airfoil chord length } \\ \mathrm{R}_{\mathrm{m}} & =\text { Reynolds number based on airfoil chord length, in millions } \\ \mathrm{R}_{\mathrm{ref}} & =\text { reference chord Reynolds number } \\ \mathrm{S} & =\text { non-dimensional arc length along the airfoil surface } \\ \mathrm{t} / \mathrm{c} & =\text { airfoil maximum thickness-to-chord ratio } \\ \mathrm{x} & =\text { stream-wise distance from the airfoil leading edge } \\ \mathrm{xtu} & =\text { prescribed upper surface transition location in ATPG, non-dimensional } \\ \mathrm{x}_{\mathrm{TR}} & =\text { transition location, non-dimensional } \\ \eta & =\text { wing span-wise location, fraction of semi-span } \\ \Lambda & =\text { leading edge sweep angle, degrees } \\ \Lambda_{\mathrm{ref}} & =\text { reference leading edge sweep angle, degrees }\end{array}$

\section{Introduction}

A s aviation moves into its second century, national research organizations such as NASA and the DLR as well as Aaircraft manufacturers are addressing the challenge of developing and implementing technologies that will produce more efficient aircraft. The impetus for this work comes from the economics of flight as fuel prices increase, as well as a concern for the environment reflected in reduced emissions and noise. An example of this emphasis is the NASA Environmentally Responsible Aviation (ERA) Project ${ }^{1}$. Figure 1 from that reference shows some of its goals relative to these areas for new aircraft in different future time frames. These goals are addressed via new concepts such as hybrid-wing body and truss-braced wing configurations as well as individual technologies in the discipline areas such as structures, materials, noise and aerodynamics.

One aerodynamic concept that is often identified as a significant potential contributor to improved aircraft performance is laminar flow. Even though there have been numerous flight demonstrations ${ }^{2}$ of both natural laminar flow (NLF) and active laminar flow control (LFC), there is currently only one implementation of it on a flying commercial aircraft to the authors' knowledge - an NLF nacelle on the Boeing 787 (Boeing also recently announced plans to offer a passive LFC horizontal tail on some models of the 787). In general, the previous flight tests focused on demonstrating the achievability of extensive regions of laminar flow without much consideration for the practicality of the resulting aircraft design, including overall performance, weight, manufacturing or system issues, especially when LFC was investigated. This is not a criticism of those efforts, as most met their goals and helped to define the potential benefit of laminar flow as well as verify analysis and design methods.

Having demonstrated that laminar flow can be obtained, however, the challenge remains of maximizing the benefit while addressing the issues that could limit its extent on a viable commercial aircraft. These include items related to manufacturing and maintenance, such as surface finish, waviness, gaps and steps, especially in the leading edge area. This may require new materials as well as manufacturing approaches, especially if LFC is required. The challenge of keeping the leading edge smooth and free of insect remains and ice crystals that could trigger premature transition has given rise to studies looking at new coatings as well as high-lift system layouts. Another key challenge is achieving significant amounts of laminar flow on a wing at cruise speeds that are typical of today's transports. This will require trade-offs between the viscous drag reduction from NLF and potential increases in wave drag due to the wing pressure architecture required to support NLF. If these limitations are not addressed, a conservative approach to implementing laminar flow will be required and the potential benefits will not be fully realized.

In an effort to address the aerodynamics-driven issues mentioned above, the development of a multi-fidelity NLF analysis and design system has been undertaken. The system uses a modular approach, with the goal of allowing different flow solvers, transition prediction methods and design modules to be selected based on the analysis or design problem and the user's experience. Two key new components of this system are: 1) a simple, empirical method for predicting n-factor growth curves in a laminar boundary layer, referred to as the Modal Amplitude Tracking and Transition Computation (MATTC) method; and 2) the Automated Target Pressure Generation (ATPG) program for developing target pressure distributions that incorporate flow and geometry constraints and can be used 
in conjunction with any design method that uses an inverse design approach. The following sections will describe these two modules as well as other components and show some results of the application of the system for analysis and design problems.

\section{Analysis Methods}

\section{A. Background}

Before describing this new approach to incorporating transition prediction into CFD analysis and design, some existing methods will be described to put our method into the context of the state of the art. The authors are aware of a number of Euler and potential flow codes that incorporate viscous effects through an interactive boundary layer computation that also include a transition prediction capability. Examples of this type of method are the MSES Euler method $^{3}$ for airfoils and TRANAIR potential flow code $^{4}$ for 3-D configurations. Work is also underway to add an interactive boundary layer with transition prediction ${ }^{5}$ to the Cart3D Cartesian grid Euler solver ${ }^{6}$. The approach typically used to predict transition is a simplified method where the transition location can be determined through table look-up or empirical curve fits to results from a boundary layer stability analysis code, using integral boundary layer parameters as the independent variables. As the boundary layer information is already available, this approach has little direct impact on the flow solution time, though convergence time can be impacted for cases where the transition location is tightly coupled with the flow state. Some potential limitations of this approach are the accuracy of the curve fits for transition prediction, the inclusion of cross-flow transition mode (e.g., using 2-D methods and simple sweep theory to design an airfoil for a wing), and the ability of the interactive boundary layer approach to accurately model the viscous effects. These methods, however, have generally proven to be efficient and have been widely used for analysis and design.

With the advent of relatively inexpensive parallel and shared-memory computing systems, the use of NavierStokes flow solvers to address viscous flow effects has increased significantly. While these codes directly address viscosity in their formulation and often have a specified transition location capability, to the authors' knowledge they seldom include a method for computing that location. One issue that arises when considering, for example, coupling one of the transition prediction methods mentioned in the preceding paragraph is how to extract the integral boundary layer parameters needed as input. Two approaches have been used to accomplish this: 1) the extraction and integration of the boundary layer profiles directly from the flow solution; and 2) the running of a separate boundary layer solver using cuts through the Navier-Stokes solution as input. An example where both of these approaches have been used for 3-D configurations is the method of Krimmelbein and Krumbein ${ }^{7}$, where the LILO linear stability analysis code ${ }^{8}$ has been coupled with the TAU unstructured grid Navier-Stokes flow solver ${ }^{9}$, with the option of running the COCO boundary-layer code ${ }^{10}$ to get boundary layer profile information. Another example of the first approach is the RATTraP method ${ }^{11}$ that is under development by Lockheed for the Air Force Research Laboratory (AFRL). Each approach has advantages and disadvantages; for example, the direct extraction method avoids the complication of having to link with a boundary layer code, but raises the issue of the proper criteria for determining the edge of a 3-D boundary layer as an integration limit and typically requires a much finer grid than normal to adequately resolve the boundary layer.

A relatively new idea for building transition prediction into a Navier-Stokes flow solver directly instead of using a coupled approach is the method of Langtry and Mentor ${ }^{12}$. This approach predicts transition using local variables from two transport equations, one for intermittency and one for a transition onset criteria related to momentum thickness Reynolds number. The method relies on empirical information to calibrate the model as opposed to modeling the physics of the transition process, but the authors show some impressive correlation with experimental results. One drawback of this method for wing design, in its current form at least, is that the crossflow (CF) mode of transition is not addressed. Also, it does not provide information on n-factor growth for possible use in design.

While the coupled methods mentioned above appear promising, they (in particular RATTraP) utilize fairly low fidelity methods for predicting transition location. This is not a criticism, as it appears that both RATTraP and LILO have an efficiency and accuracy that make them quite adequate for most analysis and design work. However, there may be cases where it would be desirable to check a design result using a higher-fidelity method, such as a linear or non-linear parabolized stability equation (PSE) solver. Discussions with researchers indicate that this type of interaction between Navier-Stokes flow solvers and higher order transition methods has been done before, but it does not appear to have been part of an automated, robust system. The goal of the current effort is to develop this type of multi-fidelity, automated system.

\section{B. Overall approach}


The overall approach for the new system consists of a loose coupling of a flow solver, transition prediction code and design method using shell scripts, along with interface modules to prepare the input for each method. This approach has been successfully used with the CDISC design method ${ }^{13}$ in the past and, though slightly less efficient than a more direct coupling of methods, allows users to select the flow solvers that they have experience with and confidence in, and provides a consistency of approach if multiple codes are used in the design project. In the development of the initial version of the system, the USM3D unstructured grid Navier-Stokes code, which, along with the VGRID grid generator and various utility codes, comprise the TetrUSS software system ${ }^{14}$, was used for 3-D configurations. The MSES Euler flow solver was used for airfoil analysis and design. The LASTRAC ${ }^{15}$ and MATTC codes were selected for transition prediction, and CDISC was used for design, both with internal constraints as well as target pressures generated using the new ATPG method. These methods, along with associated auxiliary codes, are described below.

\section{Flow Solvers}

The USM3D code is a cell-centered, finite-volume Navier-Stokes flow solver that uses Roe flux-difference splitting ${ }^{16}$ to compute inviscid flux quantities across the faces of the tetrahedral cells. Several options for turbulent closure are available: the one-equation Spalart-Allmaras (S-A) model ${ }^{17}$ (with and without a wall function), and several two-equation models, including Menter's Shear Stress Transport (SST) model ${ }^{18}$. One reason for selecting USM3D is the prior work of Pandya ${ }^{19}$ to incorporate an arbitrary transition location capability into the code. This capability would need to be present in any flow solver used in the current system but, according to Pandya, it is relatively straight-forward to add, especially the forced-laminarization method that experience to date would suggest is preferable to forced-tripping.

Currently, the flow and geometry information used by the transition prediction methods consists of pressure coefficients and airfoil coordinates extracted along stream-wise cuts through the surface grid and the flow file. This is done using an auxiliary code that reads the above files in the VGRID format used in USM3D. This format requirement should not present a significant obstacle to using other flow solvers, as converters between other formats such as PLOT3D ${ }^{20}$ and UGRID ${ }^{21}$ have been developed.

The MSES code, while not a formal part of the new system, was used extensively in the development of the MATTC and ATPG methods. This code uses a Newton method to simultaneously solve the 2-D Euler and integral boundary layer equations and includes a table look-up method for Tollmein-Schlicthing (TS) mode transition prediction. A post-processing graphics program allows the user to compare the n-factor growth predicted by the simpler internal envelope method to individual frequency growth (mode tracking) curves. A simple auxiliary code extracts output flow and geometry information and converts it into the format used for transition prediction and design in the new system.

\section{Transition prediction modules}

When considering the selection of a transition prediction module, there were two main criteria that were evaluated: availability and fidelity level(s). In terms of availability, this meant that the method must be unrestricted, at least in terms of US industry and research organizations, thus excluding company proprietary methods in the initial development (although converters could allow their inclusion at a later date). Relative to fidelity levels, the goal is to eventually provide an option for every level from simple empirical methods to linear stability theory (LST) to non-linear PSE analysis. With these options, the user could select the method most appropriate for his task - e.g., use a simple empirical method for design, then check the final result using a higher-fidelity analysis. As the current NLF design approach in ATPG uses information from the TS and CF n-factor growth curves, an additional requirement for any candidate method is that it provides this level of detail.

The LASTRAC suite of software was an obvious candidate - as a NASA-developed system it met the availability criteria, having already been distributed to a number of aerospace companies, government research labs and universities. It is actually a collection of methods ranging in fidelity from linear stability theory to linear/nonlinear PSE and secondary instability theory. LASTRAC has been used for n-factor correlation studies (including the development of empirical methods), absolute-amplitude transition analysis and receptivity computations and is applicable in all speed regimes. Based on this inherent multi-fidelity capability, it was decided to begin incorporating LASTRAC into the new system, starting with the LST level and obtaining the boundary layer information using an external boundary layer code rather than extracting profile information from the solution. This approach would allow smaller grids to be used in the initial evaluations.

In the process of integrating LASTRAC into the new system, it became apparent that, while it is a very capable code, it had some limitations relative to the goals of our new system. First, even at the lowest level of fidelity (LST), direct computation of the instability evolution, especially in a serial mode, was too slow to be used for design. In a

4

American Institute of Aeronautics and Astronautics 
test case involving the calculation of TS and CF modes for each surface at 21 span stations on a modified version of the wing on the NTF NLF model ${ }^{22}$, the time required to predict transition for the full wing using LST based on 121 wall-normal points was about 4900 seconds on a Macintosh G5 computer, even using a fairly small set (16) of frequencies and wavelengths. The wall time could be reduced through distributed processing in the future, but this still pointed to the need for a faster low-fidelity method that would not cause the transition prediction phase to dominate the process in terms of computational time.

Because LASTRAC has primarily been used in a research environment until now, additional tuning was necessary to provide the automation and robustness desired for the new system. Additional difficulties were related to the boundary layer code, BLSTA_3D ${ }^{23}$, which was used in the present study to compute the mean flow for the LASTRAC-based stability analysis. In some cases, these issues were addressed in the auxiliary code that automatically prepares the input for BLSTA_3D and LASTRAC from the flow solution and grid information. Examples of this are the conditioning of the flow near the stagnation point and the automated calculation of the frequency/wavelength ranges for TS/CF computations (LASTRAC does produce some estimates of the frequency/wavelength ranges, but the newly-developed approach seems more accurate and simplifies the process by eliminating the extra LASTRAC run to get these ranges). Additional issues were addressed in the run script itself by setting up an iterative procedure to run the module, check for a failed run, alter the input and rerun the code. While this approach allowed results to be obtained, the final system will need to address these issues directly in the codes themselves.

In addition to the input preparation code mentioned above, other auxiliary codes are used to: 1) find the envelope of the n-factor curves for the selected combinations of disturbance frequency and span-wise wavelength; 2) determine the transition location along each cut from the n-factor envelope using an prescribed value of critical $n$ factor that correlates with transition onset; and 3) output the transition front assembled from the various cuts to a file to be read into the flow solver.

To address the need for a faster low-fidelity analysis, the RATTraP method was considered. This method was developed using LASTRAC results to calibrate models similar to those used in MSES and includes both envelope and mode tracking options for developing TS and CF growth curves, along with an intermittency model and a check on attachment line instability. Currently, the only option for obtaining the boundary layer information is via profile extraction from the flow solution. This code is still considered a candidate for the new system, but further evaluation is on hold pending some ongoing work by the developer to make it more of a stand-alone module.

Meanwhile, it was decided to pursue the development of a new low-fidelity transition prediction method that could provide n-factor growth details without the need for boundary layer profiles or integral quantities, thus avoiding the issues associated with extracting this information. This approach, MATTC, is also a key component of the ATPG code and will be described in detail in the following section.

\section{E. Modal Amplitude Tracking and Transition Computation (MATTC) method}

\section{TS module}

The idea for a simple method for estimating $n$-factor distributions based on a given pressure coefficient $\left(\mathrm{C}_{\mathrm{p}}\right)$ distribution grew out of some earlier work in developing an algorithm for designing to a specified n-factor distribution. It was observed that, for TS waves, a change in n-factor level at a given location could be related to a change in the slope of the $\mathrm{C}_{\mathrm{p}}$ distribution at that same point. This concept was built into the CDISC flow constraint NLFCP and found to work fairly well in achieving a target TS n-factor distribution for 2-D airfoils as well as 3-D wing sections $\mathrm{s}^{24}$.

In view of the success of this method, further studies were made to examine the correlation between the pressure coefficient and TS n-factor growth in more detail, including the effects of Reynolds number. Several observations from this study led to the development of an initial model for TS n-factor growth. The first was that a change in $\mathrm{n}$ factor $\left(\mathrm{N}_{\mathrm{ts}}\right)$ correlated with a change in $\mathrm{C}_{\mathrm{p}}$ slope $\left(\mathrm{C}_{\mathrm{p}}{ }^{\prime}\right)$, as previously noted. Second, it appeared that the location where the n-factor growth began and/or stopped was related to a $\mathrm{C}_{\mathrm{p}}{ }^{\prime}$ threshold that was a function of chord-wise location and chord Reynolds number. A final observation was that the slope of the n-factor growth curve was related to chord Reynolds number as well as the local value of $C_{p}$.

Based on these studies, an initial, three-factor model was proposed as

$$
\Delta N t s=B \times C \times D \times \Delta x / C
$$


where $\Delta \mathrm{N}_{\mathrm{ts}}$ is the change in $\mathrm{n}$-factor over a distance $\Delta \mathrm{x} / \mathrm{c}$ along the airfoil surface. The development of the final $\mathrm{n}$ factor growth curve is computed by integrating this equation along each airfoil surface from the leading edge to the trailing edge.

A key part of the MATTC TS method is an adjustment to the $\mathrm{C}_{\mathrm{p}}{ }^{\prime}$ values, based on the Reynolds number and chord-wise location. As mentioned above, there appeared to be a threshold for the $\mathrm{C}_{\mathrm{p}}{ }^{\prime}$ term below which the TS growth would not begin or continue to grow. This level was proposed to be a polynomial function in $\mathrm{x} / \mathrm{c}$ of the form

$$
A=a_{0}\left(1+a_{1}(x / c)+a_{2}(x / c)^{2}\right)
$$

with

$$
a_{0}=-\log _{n}\left(R_{m}+1\right)^{(1-.01 * R m)}
$$

where $R_{m}$ is chord Reynolds number in millions. The procedure for determining the coefficients a1 and a2 for this equation will be described later in this section. The value of $A$ is subtracted from each $C_{p}{ }^{\prime}$ value, with any negative adjusted values then being set to zero.

The factor B incorporates the scaling effect of Reynolds number according to

$$
B=14 R_{m}^{0.5}
$$

The $\mathrm{C}$ term addresses the influence of the slope of the $\mathrm{C}_{\mathrm{p}}$ distribution according to the equation

$$
C=C_{p}{ }^{\prime}-A
$$

with $C$ set to 0 or 1 if below or above these limiting values. The final term in the equation includes the effect of $C_{p}$ level, given by

$$
D=2 /\left(C_{p a}-C_{p}\right)
$$

where $\mathrm{C}_{\mathrm{pa}}$ is the theoretical attachment line pressure coefficient.

In general, the $\mathrm{B}, \mathrm{C}$ and $\mathrm{D}$ terms were developed by trial and error using a few airfoil cases. The $\mathrm{A}$ term proved to be less amenable to this approach, so a more rigorous method was employed in evaluating its coefficients. First, three airfoils were selected for use in the development of a database: 2 airfoils designed for laminar flow (NLF $0416^{25}$ and N1, developed using CDISC), and a supercritical airfoil (D0) that had been used in multipoint design studies $^{26}$. These were selected to cover a range of Mach numbers (see design conditions in table 1) and to provide a variety of pressure distribution characteristics (see figure 2). These pressure distributions were obtained using the MSES flow solver at each airfoil's respective design Mach and lift coefficient and a Reynolds number of 1 million. In order to provide smooth pressure distributions for the stability analysis, transition was fixed at the leading edge to avoid the sudden change in $C_{p}$ that can occur in MSES at the transition point at this fairly low Reynolds number.

These pressure distributions, along with the airfoil coordinates, were fed into the automated LASTRAC method to generate the corresponding n-factor distributions at chord Reynolds numbers of $0.25,0.5,1,3,5,10$, 20, and 30 million. This provided 48 cases ( 3 airfoils $* 8$ Reynolds numbers $* 2$ surfaces) for use in determining the coefficients a1 and a2, with the a0 term fixed as a result of some initial studies. To compute these coefficients, the MATTC TS equations were incorporated into a code written in the R programming language ${ }^{27}$ to allow statistical analysis of the correlation between n-factor values from MATTC and LASTRAC. The final values of a1 $=-1.9$ and a2 $=0.6$ were determined using a minimum total mean of the absolute value of the difference between LASTRAC and MATTC n-factor values, with a uniform weighting of the differences and the calibration range limited to LASTRAC n-factor values less than or equal to 12, based on typical compressible critical n-factor levels. The TS nfactor growth curves for the 48 cases are compared with the LASTRAC results in figures 3-5. In general, the MATTC equations match the LASTRAC curves fairly well and typically differ by less than $\Delta \mathrm{x} / \mathrm{c}=0.1$ in transition location, based on a critical n-factor level of 9. 


\section{Cross-Flow (CF) Module}

While there was some confidence that the TS module could be developed based on the previous design algorithm work, it was not as clear that the CF n-factor growth could be correlated based on a simple model involving streamwise pressure architecture. An approach similar to the initial TS study was undertaken for CF, with observations that CF levels increased, in general, with stronger favorable pressure gradients as well as increasing Reynolds number and sweep. Three studies were initiated to evaluate these effects.

The first study examined the effect of pressure gradient on CF growth. The pressure distributions from the three airfoils used in the TS study were used as input to the automated LASTRAC CF analysis at a Reynolds number of 20 million and a sweep of 20 degrees. For all of the CF cases, infinite sweep wing conditions were assumed. This gave 6 cases ( 3 airfoils * 2 surfaces) for use in evaluating the following proposed equation:

$$
\Delta N c f=E \times F \times G \times H \times \Delta s
$$

where $\Delta \mathrm{s}$ is a change in non-dimensional arc length along the airfoil surface. As the CF wave growth begins at the nose of the airfoil, it was found that using arc length instead of $\mathrm{x} / \mathrm{c}$ for distances and derivatives gave better results. The $\mathrm{E}$ term in this equation is a scaling based on chord Reynolds number $\left(\mathrm{R}_{\mathrm{c}}\right)$, given by

$$
E=\left(R_{C} / R_{r e f}\right)^{e 1} .
$$

For this study, the reference Reynolds number ( $\left.\mathrm{R}_{\mathrm{ref}}\right)$ is 20 million, giving a ratio of 1 so that $\mathrm{e}_{1}$ can be set to any non-zero constant. Its value will be determined in a separate study described below. The $\mathrm{F}$ term addresses the effect of $\mathrm{C}_{\mathrm{p}}{ }^{\prime}$, with the derivative taken with respect to arc length as mentioned above. The initial term is

$$
f_{0}=-C_{p}{ }^{\prime}
$$

subject to the limitation that $\mathrm{f}_{0}<\mathrm{f}_{1}$, a maximum allowable growth rate. The final $\mathrm{F}$ term is then computed as

$$
F=f_{0} * f_{2}
$$

where $f_{2}$ is a simple scaling factor. The $G$ term includes the impact of distance from the leading edge, local velocity and compressibility and is given by

$$
G=\sqrt{s /\left(C_{p a}-C_{p}\right) /\left(1-M_{n}{ }^{2}\right)}
$$

where $\mathrm{M}_{\mathrm{n}}$ is the component of the free-stream Mach number normal to the wing leading edge. The final term, $\mathrm{H}$, accounts for the effect of sweep $(\Lambda)$ and is given by

$$
H=\left(\Lambda / \Lambda_{\text {ref }}\right)^{h 1}
$$

As with E, the reference value ( $\Lambda_{\text {ref }}$ ) is set to 20 degrees, giving a ratio of one for this study. The actual value of $h_{1}$ will be determined in a separate study described below.

The values of $f_{1}$ and $f_{2}$ were determined in a manner analogous to the $a_{1}$ and $a_{2}$ terms in the TS equations. In this case, however, the difference in n-factor levels produced by MATTC and LASTRAC were scaled by the square root of arc length before being summed to find the smallest total mean. This weighting was done to reduce the impact of mismatches in n-factor level near the leading edge, where the growth rate is very steep. This approach seemed to provide a better overall match to final levels for pressure distributions more typical of NLF airfoils. Based on this procedure and a slight adjustment to favor conservative prediction, the values $\mathrm{f}_{1}=24$ and $\mathrm{f}_{2}=36$ gave the best fit to the LASTRAC results. The resulting curves are plotted in figure 6 and appear to match the LASTRAC levels and character fairly well. It should be noted that the method used for extracting the envelope curve allows only a minimal decrease in n-factor values after a peak value is reached for both LASTRAC and MATTC data sets.

For determining the $e_{1}$ and $h_{1}$ coefficients, the LASTRAC data for the cases that were different from the reference values were scaled using the $E$ and $H$ factors, with the $e_{1}$ and $h_{1}$ values selected based on the minimum total mean of the absolute value of the difference in $n$-factor levels between the scaled curves and the original 
reference case values. Figures 7-10 show the original and scaled data for each of the cases. The scaling appears to work fairly well in general, especially for the higher values of sweep and Reynolds number where CF n-factor levels are the highest. The closeness of the $\mathrm{e}_{1}$ and $\mathrm{h}_{1}$ values to 1 and 2 , respectively, suggests that maybe these effects are actually linear and quadratic, but the results obtained from the study will be retained for now.

To evaluate the new TS and CF modules, the MATTC method was run for the same NTF NLF model configuration used earlier to evaluate the automated LASTRAC part of the multi-fidelity system. MATTC required less than 2 seconds to produce the TS and CF results for the upper and lower surfaces for the 21 stations, a reduction of over 3 orders of magnitude in comparison with direct LST computations via LASTRAC. Although a direct comparison of timing is not available with the LILO code, it is estimated to be about 2 orders of magnitude slower than MATTC, but still an order of magnitude faster than LASTRAC. The MATTC results (solid lines) at four of the wing stations are compared with results from the LASTRAC (dashed) and LILO (dotted) methods in figure 11, along with a plot of the $\mathrm{C}_{\mathrm{p}}$ distribution (green). The TS curves are shown in blue and CF in red, with span-wise location increasing from left to right and the upper surface in the top row, lower surface in the bottom row.

The MATTC results are generally in good agreement with the other two methods, especially on the lower surface. On the upper surface, the TS growth starting location is accurately predicted, but the slope, especially for the middle two wing stations, is too steep. The variation from LASTRAC is similar in magnitude to the difference between LASTRAC and LILO, though in the opposite direction. It was somewhat surprising to see the variation between the LASTRAC and LILO results at these stations, as the methods are based on a similar level of fidelity of stability analysis. One possibility is that the TS n-factor growth is very sensitive to $\mathrm{C}_{\mathrm{p}}{ }^{\prime}$ for this type to pressure distribution with a mild adverse or neutral gradient, thus accentuating any differences between the modeling in the boundary layer or stability analysis codes. For these cases at least, MATTC tends to give an earlier transition location, which is conservative.

This type of inconsistency has also been seen with the MSES code in comparisons of the internal envelope method with the post-processing plots of the higher-fidelity mode tracking method. Figure 12 gives an illustration of this, showing MSES results for the N1 airfoil at a Reynolds number of 12 million (similar to the above cases). At the design lift coefficient of 0.7, there is a mild favorable pressure gradient (see figure $2 \mathrm{~b}$ ) and the envelope method gives higher n-factor levels than the mode tracking approach in the mid-chord region (figure 12a). If the lift coefficient is increased to 0.8 to reduce the favorable pressure gradient on the upper surface (figure 12b), the situation is reversed and the mode tracking method now gives the higher n-factor levels. This example, along with the results shown in figure 11, serves to reinforce the need for a multi-fidelity transition prediction capability.

As a result of seeing this type of inconsistency in results from different stability analysis methods, the authors believe that a transition prediction workshop, perhaps similar to the AIAA Drag Prediction Workshop, might be of benefit to the laminar flow community. Flow and geometry information could be developed from simple analytical models, CFD runs and/or wind tunnel tests. Boundary layer mean flow data could also be provided to help isolate the cause of any discrepancy in the results of the different codes. In addition, the data sets could be used to evaluate and perhaps improve the simplified methods such as MATTC that are being developed.

In summary, the initial development of the MATTC low-fidelity transition prediction module and automation of the running of the higher-fidelity LASTRAC code are complete. The auxiliary codes linking these modules into the system have been run and appear to be functioning properly. An operational evaluation of the complete system is now underway.

\section{Design Methods}

In an effort to make the new system usable by as broad a user base as possible, it was decided to focus the design portion on the use of target pressures. This would allow knowledge-based or inverse design methods, as well as numerical optimization codes, to be selected for design. For the initial development of this system, the CDISC design method was chosen and is described below.

\section{A. CDISC}

The CDISC module is a knowledge-based design method that has been coupled with a variety of 2-D and 3-D flow solvers ranging from potential flow to Euler/Navier-Stokes and, for the latter category, has been used with structured, overset, unstructured and Cartesian grids. The code uses specified flow/geometry relationships developed from analytical or empirical studies to compute geometry changes based on the difference between current and target flow quantities. This eliminates the need to compute sensitivity derivatives and allows the design to converge in parallel with the flow solution, thus greatly reducing the time required for a design. The design time is further reduced by the use of flow constraints to automatically develop the target distribution from the current values of 
flow quantities such as pressure or skin-friction coefficients. These constraints address common engineering design variables such as span load, section lift and pitching moment coefficients, and shock strength. This approach has generally been more robust than manually specifying a fixed input target pressure in that it tends to avoid problems such as an incorrectly specified attachment line location or pressure level. In addition to the flow constraints, geometry constraints such as thickness, curvature, volume and leading edge radius are available to address requirements from other disciplines such as structures and manufacturing.

Two flow constraints are available within CDISC for TS-dominated NLF design. The first is the OROOF constraint, originally developed for turbulent transonic airfoil design, with the supercritical rooftop pressure distribution having a mild adverse gradient to minimize shock strength (see figure 13a, +OROOF case). For laminar flow design, the parameter that controls the slope of the rooftop is automatically adjusted to move the transition point to the desired location. For moderate to high Reynolds numbers, this approach typically produces a favorable pressure gradient (-OROOF in figure 13a) and a fairly linear TS growth curve (figure 13b).

A second option, the NLFCP constraint, provides the user with more control over the n-factor distribution. The basis for this constraint is the observation that a change in Cp slope was generally proportional to a change in $\mathrm{n}$ factor level, as noted in the section on MATTC. As input, the user specifies the start point $\left(\mathrm{x}_{0}, \mathrm{~N}_{0}\right)$, end point $\left(\mathrm{x}_{\mathrm{TR}}\right.$, $\mathrm{N}_{\mathrm{TR}}$ ), and exponent (NFE) for a polynomial to define a target $\mathrm{n}$-factor distribution, given by

$$
N=N_{0}+\left(\left(x-\chi_{0}\right) /\left(x_{T R}-\chi_{0}\right)\right)^{N F E}\left(N_{T R^{-}}-N_{0}\right)
$$

Ahead of the starting point, no constraint is applied to the n-factor growth. Figure 14a shows n-factor growth curves for three values of the $n$-factor exponent with the same start and end points, with the corresponding pressure distributions shown in figure $14 \mathrm{~b}$.

The drag polars for these cases, shown in figure 14c, indicate very different characteristics for the 3 values of NFE. The NFE $=0.25$ case shows a rapid increase in drag coefficient at lift coefficients just above the design value of 0.7. This is not surprising, as the target n-factor was fairly close to the critical n-factor level of 9 over the front of the airfoil at the design point and a small decrease in the favorable pressure gradient due to increasing lift coefficient pushes these $n$-factors above the limit at a forward location. The NFE $=1$ case is similar to the $n$-factor distribution produced by OROOF and has a benign, fairly linear increase in drag above the design point. The NFE $=8$ case has the widest laminar drag "bucket", with the low-drag region extending from a lift coefficient of about 0.5 to almost 0.9 , where the drag rise is again fairly sudden as with the NFE $=0.25$ case. One possible strategy for using this method would be to specify a low NFE value for the upper surface at the high end of the cruise lift coefficient range and for the lower surface at the lowest cruise lift coefficient as part of a dual-point design. It should be noted again that this case is only considering the TS transition mode and that the pressure distributions that produced good drag characteristics would probably have an adverse effect on CF growth, thus requiring some trades if this mode was active. The MATTC work would suggest that a constraint similar to NLFCP could be developed for CF design as well.

\section{B. ATPG}

In the above cases using the OROOF and NLFCP constraints, the goal was to achieve a given transition location for a specified lift, pitching moment and thickness without regard for the drag of the airfoil. For a practical aircraft design at transonic conditions, however, the drag at cruise is a key factor, along with other considerations such as climb performance, drag rise and buffet margin. For an aircraft with NLF, the favorable rooftop gradient required to extend laminar flow on the upper surface will, at some conditions, begin to cause an increase in wave drag relative to a all-turbulent wing design.

This trade between the wave drag and viscous drag to minimize total drag is something that numerical optimization should be able to automatically address, but is currently not part of the CDISC flow constraint set. Recognizing that this would also be a useful capability for knowledge-based and inverse design methods in general, the authors began jointly developing the ATPG module under a cooperative agreement between NASA and the German Aerospace Center (DLR). The primary goal for this module is to automatically generate an NLF target pressure distribution that will have the extent of laminar flow that results in the minimum total drag while also enforcing flow and geometry constraints such as lift and thickness. The development and implementation of these two objectives are discussed below.

\section{Constraints}

The flow constraint strategy in ATPG is similar to that used in CDISC, in that the target pressure distribution is developed from the current pressure distribution. This approach helps to avoid inconsistent pressure specification in 
regions such as the leading and trailing edges and also implicitly includes the effects of any geometry constraints such as thickness. The current flow constraint options include lift, pitching moment, upper surface shock location and upper and lower surface transition locations. Lift is matched by modifying the region from near the leading edge to the upper surface shock (or transition location for a subcritical case) using a constant increment, thus maintaining the desired pressure gradient for laminar flow and/or a weak shock imposed by other constraints. Blending functions are applied at each end of this region to maintain a smooth target distribution. Pitching moment is adjusted through a function that produces aft loading similar to supercritical airfoils. Shock location can either be explicitly input or automatically determined internally using an empirical formula based on Mach number and lift coefficient.

For the transition location constraints, the MATTC TS and CF modules are first called to determine the nfactor growth characteristics (a check is also made for early transition due to attachment line instability). Based on the results from the study using the CDISC NLFCP constraint discussed above, a variable critical n-factor approach was implemented to avoid designs having abrupt shifts in transition location for minor variations from the design conditions. With this method, the user specifies a lower critical n-factor level at the leading edge (typically about 1 for TS), which will then linearly increase to the normal critical n-factor at the desired transition location (see black dotted line in figure 15). This will produce $n$-factor growth curves similar to the NFE $=1$ case in the NLFCP study. For the CF mode, the initial critical n-factor level is on the order of half of the transition value, as the n-factor growth rate typically is large near the leading edge and attempting to suppress it too much can produce impractical target pressures. For both TS and CF modes, the target pressures are primarily adjusted using simple triangular pressure increments based on the current and desired transition locations.

There are also several hard-wired constraints on the pressure gradients at different locations on the airfoil that were added to improve the robustness and performance of the design process. An example of this is a maximum allowable pressure gradient on the upper surface near the trailing edge. This value is set based on stream-wise location and free-stream Reynolds number and is intended to reduce the possibility of trailing edge separation. The implementation of this type of constraint is tentative at this point and needs further evaluation.

The target pressure distribution is developed from the current analysis pressures by sequentially applying the above constraints to the current analysis pressures in an iterative manner until all of them are met within a specified tolerance or the iteration limit is reached. As this can require hundreds of iterations, the need for a very rapid transition prediction method such as MATTC becomes obvious.

Currently, the only user-specified geometry constraint is maximum thickness-to-chord ratio, with an option of specifying the chord-wise location for enforcing the desired value. The input value is explicitly matched through the scaling of the airfoil coordinates, which are then output along with the target pressures for use in the next CDISC design cycle. In addition to this direct thickness constraint, the desired value is also implicitly held constant in the development of the target pressures by constraining the average of the upper and lower surface pressures at the location of maximum thickness. As mentioned above, this process is self-calibrating, in that the target pressures are recomputed from the current pressure distribution after each design cycle. An option for a leading-edge radius constraint is under development, though the current process tends to produce airfoil nose shapes that are compatible with laminar flow. In an effort to ensure robustness of the design process, especially during early design cycles, the thickness of the airfoil over the last 30 per cent of the chord is maintained above a prescribed level based on maximum airfoil thickness.

\section{Drag minimization}

Historically, one of the primary uses of the CDISC method has been the reduction of wave drag in transonic design by weakening shocks using a flow constraint such as OROOF. A similar capability, using a polynomial function to prescribe the supercritical rooftop pressures, has been incorporated into ATPG. This function provides a mild adverse pressure gradient on the airfoil upper surface for turbulent design cases. It is also used to set the initial pressures for an NLF design, which are then modified using the methods described in the previous section to obtain the specified transition location.

One approach to transonic NLF drag minimization would be to simply step through a series of designs using different transition locations and select the one having the minimum total drag. This could be automated in a fairly efficient manor for airfoils, using solution restarts for successive designs since the target pressures would not change much for a small step in transition location. This approach becomes less viable, however, for wing design as the number of design stations increases.

A more efficient approach would be to optimize the target pressure distribution itself, using empirically derived estimates of the different components of drag. These components include the wave drag mentioned above and the drag due to skin friction, which is reduced in regions of laminar flow. An additional benefit of laminar flow is the thinning of the subsequent turbulent boundary layer, which gives a reduction in profile drag that is often of larger 
magnitude than the skin friction drag reduction. This approach was used in previous work ${ }^{28}$ for wave drag but did not include the viscous drag components.

A series of studies similar to those used in the development of the MATTC modules were conducted to develop empirical relations for the above drag components. For each study, results were obtained using MSES for a variety of airfoils over a range of flow conditions. A proposed model was then analyzed using statistical methods to determine the coefficient values that gave the best fit to the MSES data.

In reference 28, a model for wave drag based on the shock Mach number $\left(\mathrm{M}_{1}\right)$ and thickness-to-chord ratio ( $\left.\mathrm{t} / \mathrm{c}\right)$ was proposed as

$$
c_{d w}=A\left(M_{1}-1\right)^{4}
$$

where $\mathrm{c}_{\mathrm{dw}}$ is the wave drag coefficient and the leading coefficient is given by

$$
A=0.04 /(t / c)^{1.5}
$$

Although this equation worked well for the NACA 4-digit airfoil series (see figure 5 in that reference), the effects of airfoil surface curvature under the shock were not directly taken into account and can be significant. For modern airfoils, the local surface curvature is not as consistently related to thickness as with the NACA series and moderate curvature variations in the region of a shock are not uncommon. It was therefore decided to use a similar equation

$$
c_{d w}=a_{1}\left(M_{1}-1\right)^{a 2} / k
$$

where $\mathrm{k}$ is the surface curvature at the shock location (positive convex into the flow) and is restricted to be greater than 0.1 . This restriction avoids the potential singularity at $\mathrm{k}=0$ and is consistent with well-designed airfoils. The NACA 4-digit series was used for calibration and gave $\mathrm{a}_{1}=0.49$ and $\mathrm{a}_{2}=4.39$ based on linear regression analysis. Results for this equation are shown for the calibration series in figure 16a and indicate a good fit through the calibration range of $c_{d w}=0$. to .002 with a coefficient of determination $\left(\mathrm{R}^{2}\right)$ value of 0.995 . Above this range, the equation tends to over-predict the actual drag values. As an independent evaluation of the equation, several supercritical airfoils were then analyzed and the results are shown in figure 16b. Though there is more scatter in the data, the fit is still fairly good $\left(\mathrm{R}^{2}=0.922\right)$ in the calibration range below $\mathrm{c}_{\mathrm{dw}}=0.002$, which is the primary range of interest for cruise design.

For the skin friction and pressure drag components, several NLF airfoils were analyzed in MSES for various Reynolds and Mach numbers. For each case, a fixed transition location on each surface was stepped from the leading edge to the location of natural transition using 0.1 chord increments, and the changes in friction and pressure drag were recorded. It should be noted that the pressure drag increments may also contain changes in wave drag; however, the test cases were either subcritical or had very weak shocks, so this effect should be small. For these two drag components, then, the ATPG method will not give an absolute drag value but rather the drag reduction due to laminar flow compared to a fully turbulent airfoil.

The proposed equation for skin friction had only a single unknown that was determined using a linear regression anchored at 0 , with the resulting equation being

$$
c_{d f}=0.032 x_{t r}\left(M / M_{\infty}\right) / \log _{n}\left(R_{c}\right)
$$

where $x_{t r}$ is the transition location in terms of $\mathrm{x} / \mathrm{c}, \mathrm{M}$ and $\mathrm{M}_{\infty}$ are the local and free-stream Mach numbers, respectively, and $\mathrm{R}_{\mathrm{C}}$ is the chord Reynolds number.

The profile drag equation was similar, but included a term related to the magnitude of the pressure rise from the pressure minimum $\left(\mathrm{C}_{\mathrm{pm}}\right)$ to the trailing edge $\left(\mathrm{C}_{\mathrm{pte}}\right)$ and changed the effect of Reynolds number from logarithmic to an inverted exponential. A linear regression was again used to determine the best values of the leading coefficient and the exponent, resulting in

$$
c_{d p}=0.20 x_{t r}\left(M / M_{\infty}\right)\left(C_{p t e}-C_{p m}\right) / R_{C}^{0.28}
$$


The quality of the curve fits can be seen in figure 17. The friction drag data is tightly clustered around the ideal fit line (blue, figure 17a), though the range of data is small. More scatter is observed in the pressure drag plot (figure 17b), but the fit is still typically within a drag count (0.0001 in $\left.C_{d}\right)$.

\section{Demonstration case}

This initial version of ATPG was used to demonstrate the trade between wave and viscous drag in transonic airfoil design. The D0 supercritical airfoil from previous studies was used as a baseline. Four upper surface transition locations were run in ATPG at a chord Reynolds number of 20 million. The original lift coefficient (0.7), pitching moment coefficient (-0.14) and maximum t/c (0.12) from the D0 design were used as constraints here as well. The ATPG code was run at Mach numbers of $0.75,0.76$ and 0.77 , which gave Korn parameter ${ }^{29}(\mathrm{~K})$ values of 0.94, 0.95 and 0.96, respectively, where the Korn parameter is defined as

$\begin{array}{ccccc}K & = & M_{\infty} & + & 0.1 c_{l}\end{array}$

and is commonly used in transonic airfoil design. The original D0 design had a $\mathrm{K}$ value of 0.95 as well and is considered a nominal value for a modern airfoil design.

Figure 18 shows the resulting values for the different drag components as well as the total drag as a function of upper surface transition location (xtu) for the three cases. The skin friction and pressure drag components each show a fairly linear increase in drag reduction with transition location (figures 18b and 18c), but indicate very little effect of the K parameter. The wave drag component, however, shows significantly more of an increase in drag with transition location as the value of $\mathrm{K}$ is increased (figure18a). As seen in the plot of total drag versus transition location (figure 18d), this produces different optimum extents of laminar flow for the different $\mathrm{K}$ values.

The target pressure distributions for the $\mathrm{K}=0.96$ case corresponding to the optimum (xtu=0.3) and maximum $(x t u=0.5)$ extents of laminar flow are show in figure 19. The stronger shock resulting from the need to maintain the favorable pressure gradient further aft on the upper surface for the xtu $=0.5$ case can be seen, although in general the distributions are very similar.

One concern with this type of NLF design is that, while the increased wave drag tends to be balanced by viscous drag reduction at cruise conditions, the increased shock Mach number may lead to earlier deterioration of off-design performance. To investigate this further, the optimum case for the $\mathrm{K}=0.95$ design ( $\mathrm{xtu}=0.4$ ) will be compared with the D0 airfoil, which is an all-turbulent design at the same $\mathrm{K}$ value. The pressure distributions at the design condition are shown in figure 20, with the D0 (baseline) having a prominent leading edge peak and a weaker shock. The two airfoils were then run in MSES to create drag rise and drag polar plots (figure 21). The values of wave drag are shown as dashed lines and total drag as solid lines on the plot. The D0 airfoil was run with transition fixed at the leading edge, while the NLF design was restricted to transition no further aft than $\mathrm{x} / \mathrm{c}=0.4$.

The drag rise plot (figure 21a) indicates that the ATPG NLF design maintains drag levels below the baseline throughout the range of Mach numbers shown. For Mach numbers below 0.71, the baseline D0 airfoil has the wave drag "hump" associated with double shocks that tend to occur for this type of concave rooftop pressure distribution at Mach numbers below the design condition. While there is some drag creep that occurs for the NLF airfoil below the design Mach number, it does not appear to lead to an earlier drag rise Mach number, but instead appears to give slightly better characteristics. Some of this may be due to the slightly lower wave drag levels for the NLF design above a Mach number of 0.77 , but a contributor may also be the thinner boundary layer over the aft part of the airfoil that could delay trailing edge separation.

A similar situation is seen on the drag polar (figure 21b), where the new design has lower drag across the range of lift coefficients shown. Although the NLF airfoil has higher wave drag for lift coefficients below 0.8, the viscous drag reduction keeps the total drag level lower. Above a lift coefficient of 0.8, the baseline has higher drag levels, indicating a reduced buffet margin as well. It would appear, at least from this brief study, that the ATPG code may be a useful tool for NLF design and perhaps for evaluating the effect of laminar flow on the Korn parameter for use in conceptual design studies.

\section{Concluding Remarks}

An initial version of a multi-fidelity NLF analysis and design system has been completed and evaluation is underway. The two key components that required extensive development, the Modal Amplitude Tracking and Transition Computation (MATTC) and Automated Target Pressure Generation (ATPG) codes, are functional and initial results appear promising. Comparisons of TS and CF n-factor growth curves from MATTC with results from 
other established boundary layer stability analysis methods indicate that it is reasonably accurate while providing a significant reduction in the computational time required. This low-fidelity method will complement the higher fidelity analysis provided by the LASTRAC code. Initial work has also been completed in the automation of the running of the linear stability theory option in LASTRAC and of its interaction with the USM3D flow solver. The ATPG method has demonstrated the ability to develop target pressures that meet a transition location requirement as well as other flow and geometry constraints. Initial results indicate that it can also adjust constraints to minimize total drag and may be useful in developing a design criterion similar to the Korn equation but with perhaps better accuracy. Work is continuing in the application of the current multi-fidelity system to NLF wing design and incorporating some of the higher-fidelity stability analysis options in LASTRAC into the system.

\section{Acknowledgements}

The authors would like to gratefully acknowledge the support of Meelan Choudhari and Chau-Lyan Chang at NASA Langley in running the LASTRAC code and their comments on the multi-fidelity NLF analysis system. The many helpful discussions on laminar flow design with DLR colleagues Martin Hepperle, Martin Kruse, Benjamin Rodax, Arne Seitz and Georg Wichmann were also greatly appreciated. Finally, we would like to thank the NASA Environmentally Responsible Aviation Project and the DLR Braunschweig management for their support of this cooperative effort.

\section{References}

${ }^{1}$ Washburn, Anthony: NASA's Current Plans for ERA Airframe Technology; Presentation at $48^{\text {th }}$ AIAA Aerospace Sciences Meeting, January 4, 2010. http://www.aeronautics.nasa.gov/pdf/asm_2010_washburnv4x_508.pdf

${ }^{2}$ Joslin, Ronald D.: Oveview of Laminar Flow Control; NASA TP-1998-208705, October 1998.

${ }^{3}$ Drela, Mark: Newton Solution of Coupled Viscous/Inviscid MultiElement Airfoil Flows, AIAA 90-1470, June 1990.

${ }^{4}$ Jou, W. H., Huffman, W. P., Young, D. P., Melvin, R. G., Bieterman, M. B., Hilmes, C. L. and Johnson, F. T., "Practical Considerations in Aerodynamic Design Optimization,” AIAA 95-1730, July 1995.

${ }^{5}$ Desktop Aeronautics, Inc., "High Fidelity Aerodynamic Design with Transition Prediction, Phase II Final Report", NASA Contract SBIR 2006-2 NNL08AA08C, July 26, 2010.

${ }^{6}$ Melton, John E.; Berger, Marsha J.; Aftosmis, Michael J.; and Wong, Michael D.: 3D Applications of a Cartesian Grid Euler Method. AIAA 95-0853, January 1995.

${ }^{7}$ Krimmelbein, Normann; and Krumbein, Andreas: Automatic Transition Prediction for Three-Dimensional Configurations with Focus on Industrial Application. AIAA 2010-4292, June 2010.

${ }^{8}$ Schrauf, G., “LILO 2.1. User’s Guide and Tutorial,” Tech. rep., 2006, GSSC Technical Report 6, originally issued Sep. 2004, modified for Version 2.1.

${ }^{9}$ Schwamborn, D., Gerhold, T., and Heinrich, R., “The DLR TAU-Code: Recent Applications in Research and Industry,” European Conference on Computational Fluid Dynamics. ECCOMAS CFD 2006, edited by P. Wesseling, E. Onate, and J. Periaux, 2006.

${ }^{10}$ Schrauf, G., "COCO - A program to compute velocity and temperature profiles for local and nonlocal stability analysis of compressible, conical boundary layers with suction,” Tech. rep., 1998, ZARM Technik Report.

${ }^{11}$ Davis, Myron B.: Rapid Assessment Tool for Transition Prediction (RATTraP), AFRL-RB-WP-TR-2008-3070.

${ }^{12}$ Langtry, Robin B.; and Mentor, Florian R.: Correlation-Based Transition Modeling for Unstructured Parallelized Computational Fluid Dynamics Codes. AIAA Journal, Vol. 47, No. 12, December 2009, pp. 2894-2906.

${ }^{13}$ Campbell, Richard L., "Efficient Viscous Design of Realistic Aircraft Configurations,” AIAA-98-2539, June 1998.

${ }^{14}$ Frink, N.T., Pirzadeh, S.Z., Parikh, P.C., Pandya, M.J., and Bhat, M.K., "The NASA Tetrahedral Unstructured Software System,” The Aeronautical Journal, Vol. 104, No. 1040, October 2000, pp.491-499.

${ }^{15}$ Chang, C.-L., "The Langley Stability and Transition Analysis Code (LASTRAC): LST, Linear and Nonlinear PSE for 2-D, Axisymmetric, and Infinite Swept Wing Boundary Layers,” AIAA Paper 2003-0974, 2003.

${ }^{16}$ Roe, P., "Characteristic Based Schemes for the Euler Equations," Annual Review of Fluid Mechanics, Vol. 18, 1986, pp. 337-365.

${ }^{17}$ Spalart, P., and Allmaras, S.A., ”One-equation turbulence model for aerodynamic flows,” AIAA 92-0439, January 1992.

${ }^{18}$ Menter, F.R., "Improved Two-Equation k-omega Turbulence Models for Aerodynamic Flows,” NASA TM-103975, October 1992.

${ }^{19}$ Pandya, Mohagna J.; Abdol-Hamid, Khaled S.; Campbell, Richard L.; and Frink, Neal T.: Implementation of Flow Tripping Capability in the USM3D Unstructured Flow Solver. AIAA-2006-0919, January 2006.

${ }^{20}$ http://www.grc.nasa.gov/WWW/wind/valid/plot3d.html

${ }^{21}$ http://www.simcenter.msstate.edu/docs/solidmesh/ugridformat.html

${ }^{22}$ Crouch, Jeffery D.; Sutanto, Mary I.; Witkowski, David P; Watkins, A. Neal; Rivers, Melissa B; and Campbell, Richard L: Assessment of the National Transonic Facility For Laminar Flow Testing. AIAA 2010-1302, January 2010.

${ }^{23}$ Wie, Y.-S., “BLSTA: A Boundary Layer Code for Stability Analysis,” NASA CR 4481, 1992. 
${ }^{24}$ Campbell, Richard L.; Pandya, Mohagna J.; and Campbell, Matthew L.: An Efficient Approach to Natural Laminar Flow Design. Presentation at the Royal Aeronautical Society Aerodynamics Conference, July 2010, CD.

${ }^{25}$ Somers, Dan M.: Design and Experimental Results for a Natural-Laminar-Flow Airfoil for General Aviation Applications. NASA TP 1861, June 1981.

${ }^{26}$ Li, W.; Krist, S.; and Campbell, R.: Transonic Airfoil Shape Optimization in Preliminary Design Environment. AIAA Journal of Aircraft, Vol. 43, No. 3, May-June, 2006.

${ }^{27}$ An Introduction to R - Notes on R: A Programming Environment for Data Analysis and Graphics, Version 2.13.0 (201104-13). http://cran.r-project.org/doc/manuals/R-intro.pdf

${ }^{28}$ Campbell, R. L.: A New Approach to Constrained Aerodynamic Design With Application to Airfoils. NASA TP 3260, November 1992.

${ }^{29}$ Mason, William H.: Reflections on Over 20 Years of Aircraft Design Class. AIAA 2010-9065, September 2010.

\begin{tabular}{|c|c|c|}
\hline Airfoil & Mach & Lift coefficien \\
\hline JLF-0416 & 0.20 & 0.4 \\
\hline N1 & 0.65 & 0.7 \\
\hline D0 & 0.76 & 0.7 \\
\hline
\end{tabular}

Table 1 - Analysis conditions for pressure distributions used in MATTC development.

\section{ERA Project}

Goals and Metrics and System Studies

\begin{tabular}{|c|c|c|c|}
\hline $\begin{array}{l}\text { CORNERS OF THE } \\
\text { TRADE SPACE }\end{array}$ & $\begin{array}{l}\mathrm{N}+1=2015^{\star \star \star} \\
\text { Technology Benefits Relative } \\
\text { To a Single Aisle Reference } \\
\text { Configuration }\end{array}$ & $\begin{array}{l}\mathrm{N}+2=2020^{* \star *} \\
\text { Technology Benefits Relative } \\
\text { To a Large Twin Aisle } \\
\text { Reference Configuration }\end{array}$ & $\begin{array}{c}\mathrm{N}+3=2025^{+*+} \\
\text { Technology Benefits }\end{array}$ \\
\hline $\begin{array}{c}\text { Noise } \\
\text { (cum below Stage 4) }\end{array}$ & $-32 \mathrm{~dB}$ & $-42 \mathrm{~dB}$ & $-71 \mathrm{~dB}$ \\
\hline $\begin{array}{l}\text { LTO NO }_{x} \text { Emissions } \\
\text { (below CAEP 6) }\end{array}$ & $-60 \%$ & $-75 \%$ & better than $-75 \%$ \\
\hline $\begin{array}{c}\text { Performance: } \\
\text { Aircraft Fuel Burn }\end{array}$ & $-33 \% * *$ & $-40 \%$ ** & better than $-70 \%$ \\
\hline $\begin{array}{l}\text { Performance: } \\
\text { Field Length }\end{array}$ & $-33 \%$ & $-50 \%$ & exploit metro-plex ${ }^{*}$ concepts \\
\hline \multicolumn{4}{|c|}{$\begin{array}{l}\text { *** Technology Readiness Level for key technologies }=4-6 \\
\text { ** Additional gains may be possible through operational improvements } \\
\text { * Concepts that enable optimal use of runways at multiple airports within the metropolitan area }\end{array}$} \\
\hline \multicolumn{4}{|l|}{ ERAApproach } \\
\hline \multicolumn{4}{|c|}{$\begin{array}{l}\text { - Focused on N+2 Timeframe - Fuel Burn, Noise, and } \mathrm{NO}_{x} \text { System-level Metrics } \\
\text { - Focused on Advanced Multi-Discipline Based Concepts and Technologies } \\
\text { - Focused on Highly Integrated Engine/Airframe Configurations for Dramatic Improvements }\end{array}$} \\
\hline
\end{tabular}

Figure 1 - Technology benefit goals for future aircraft in the NASA Environmentally Responsible Aviation (ERA) Project (from reference 1). 


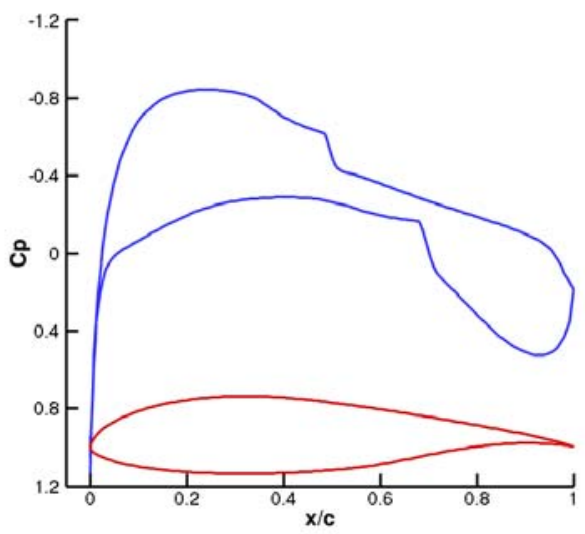

a) NLF-0416

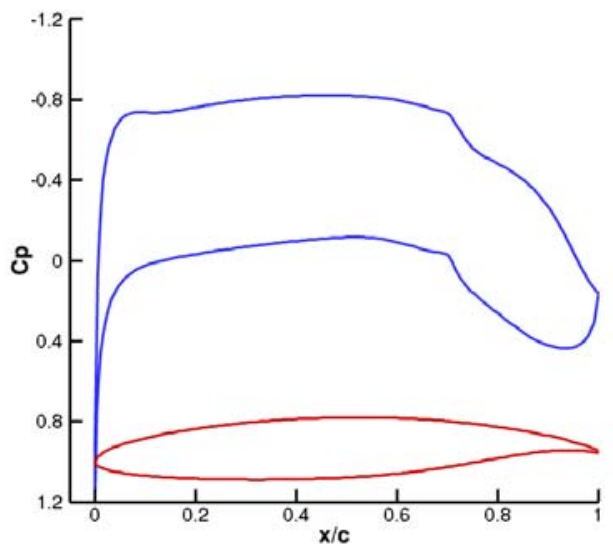

b) N1

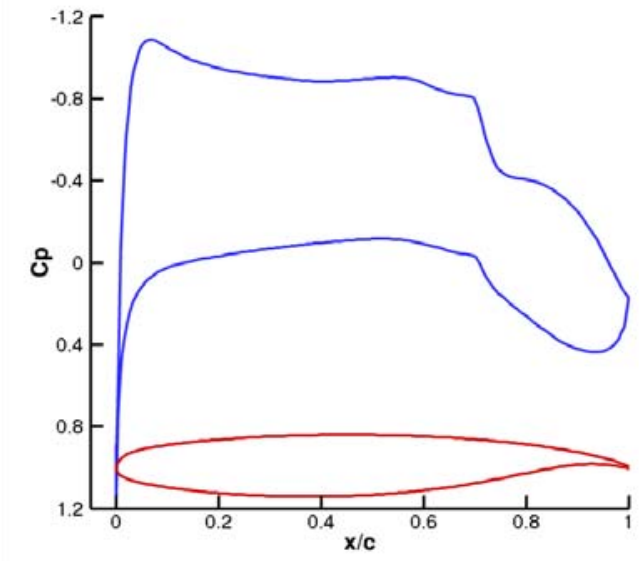

c) $\mathrm{D} 0$

Figure 2 - Airfoils and pressure distributions used in the development of the MATTC TS and CF modules. 

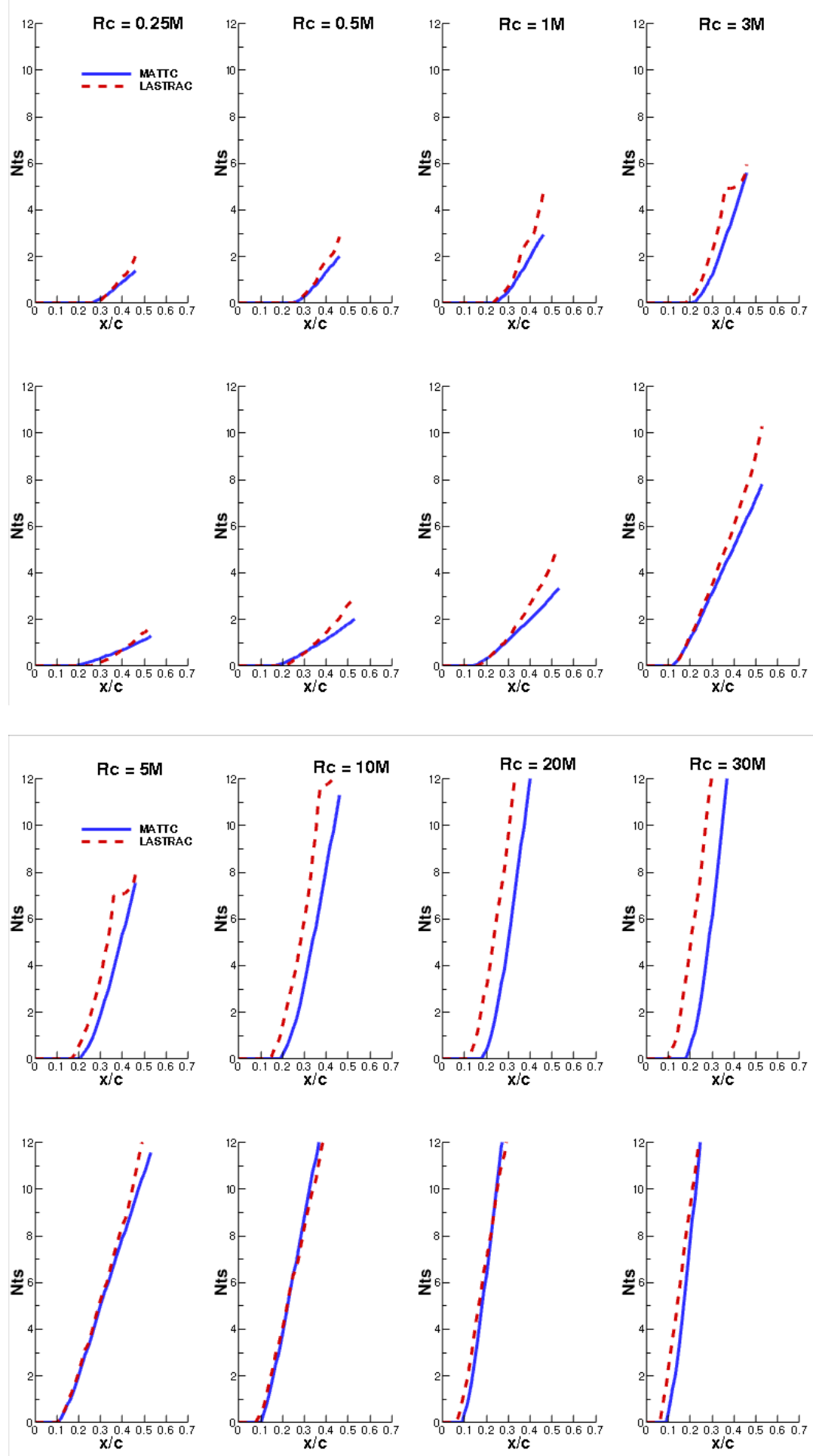

Figure 3 - Comparison of MATTC and LASTRAC TS n-factor growth curves for the NLF-0416 airfoil. Upper two rows in figure are for Reynolds numbers from 0.25 to 3.0 million (left to right), with top row showing upper surface and $2^{\text {nd }}$ row showing lower surface. Bottom two rows are similar format for Reynolds numbers from 5.0 to 30 million. 

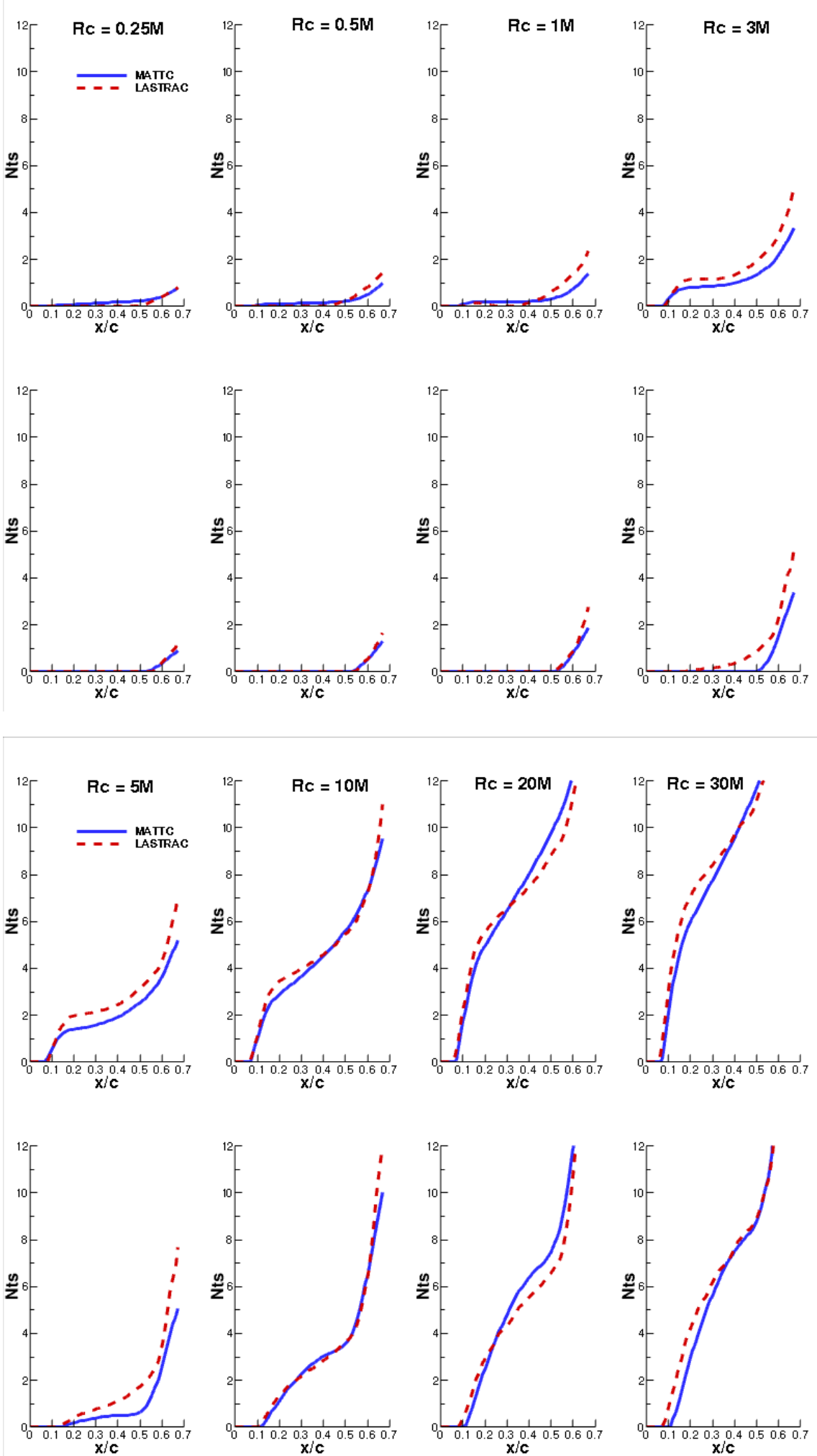

Figure 4 - Comparison of MATTC and LASTRAC TS n-factor growth curves for the N1 airfoil. Upper two rows in figure are for Reynolds numbers from 0.25 to 3.0 million (left to right), with top row showing upper surface and $2^{\text {nd }}$ row showing lower surface. Bottom two rows are similar format for Reynolds numbers from 5.0 to 30 million. 

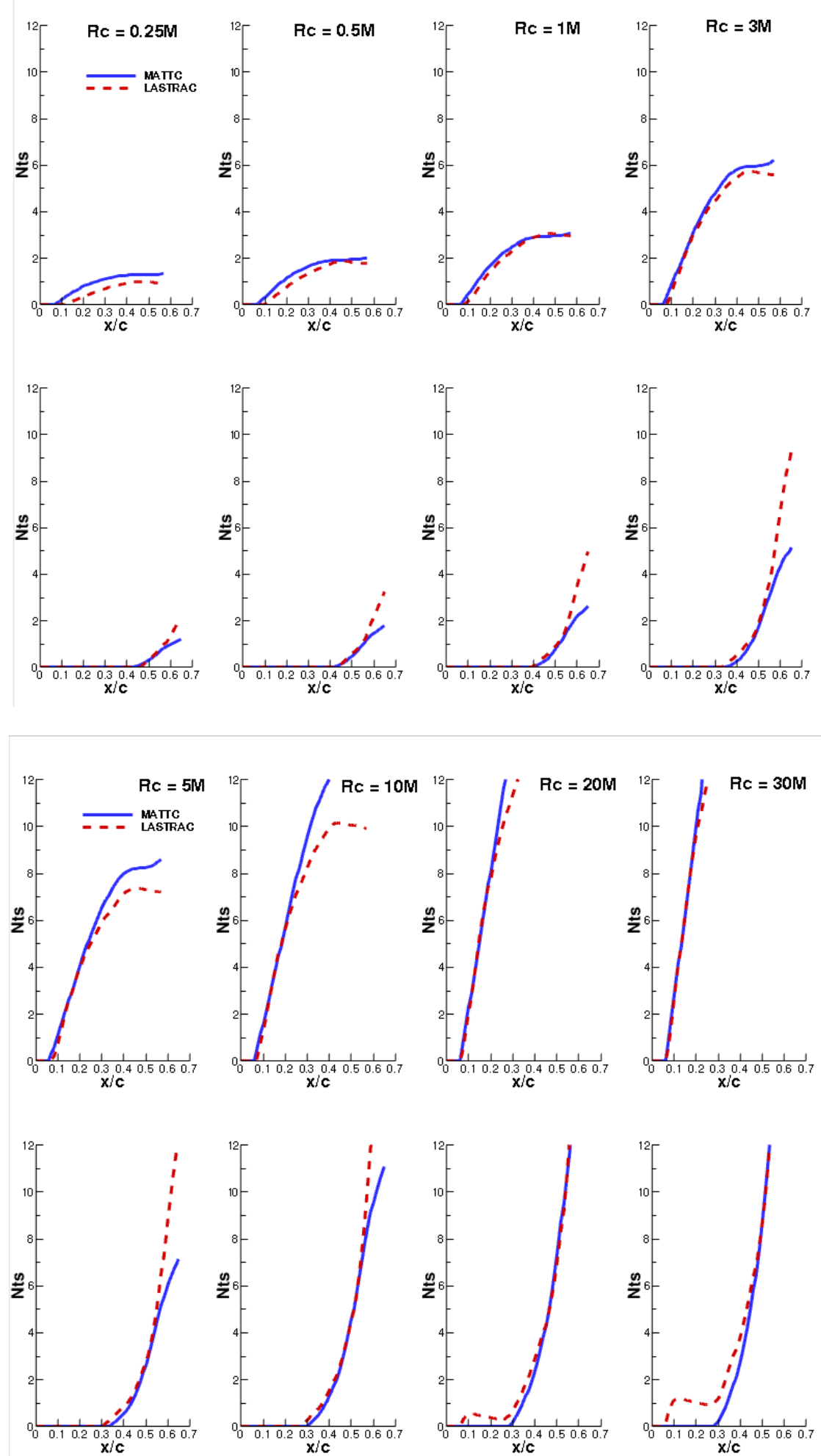

Figure 5 - Comparison of MATTC and LASTRAC TS n-factor growth curves for the D0 airfoil. Upper two rows in figure are for Reynolds numbers from 0.25 to 3.0 million (left to right), with top row showing upper surface and $2^{\text {nd }}$ row showing lower surface. Bottom two rows are similar format for Reynolds numbers from 5.0 to 30 million. 

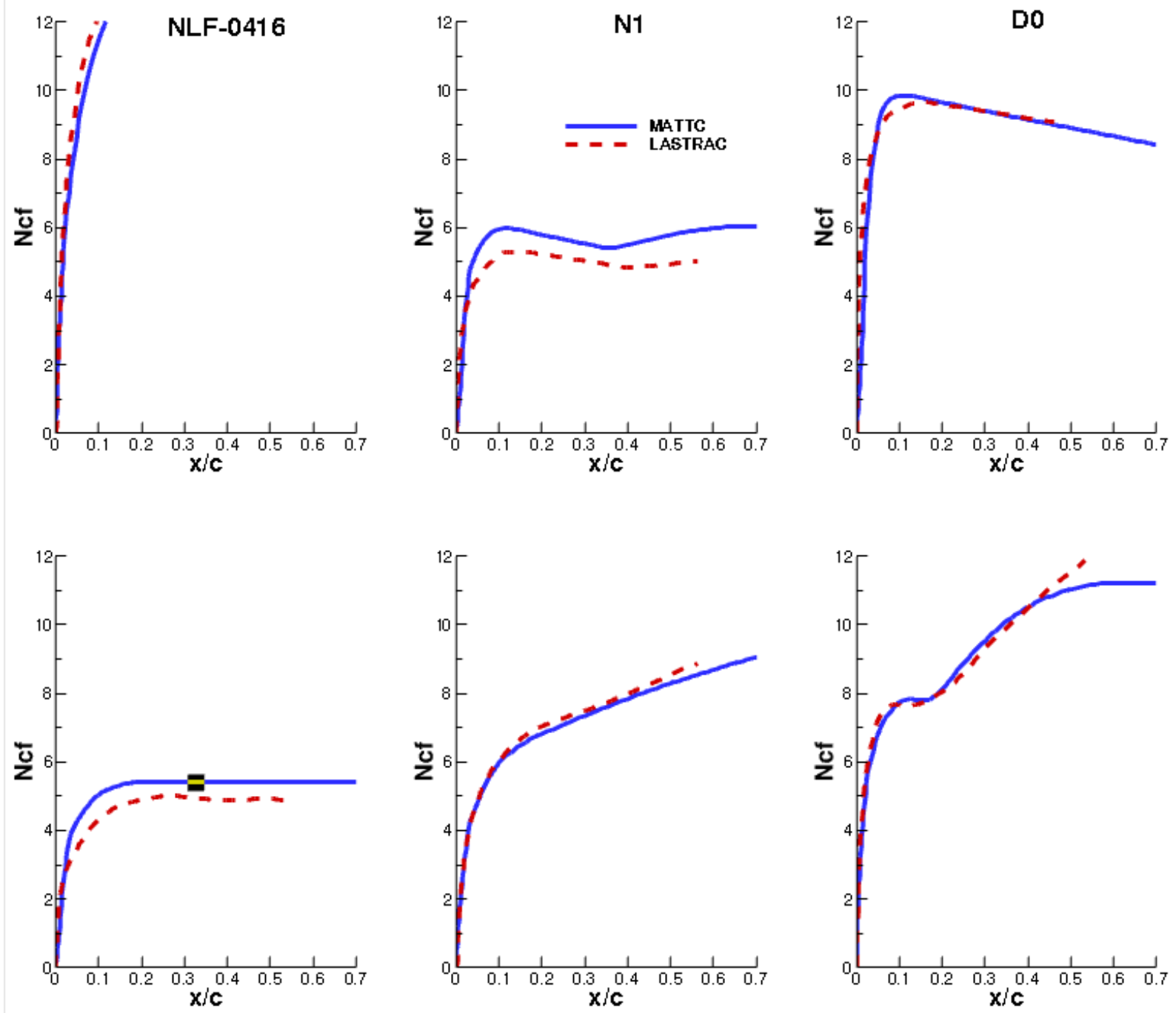

Figure 6 - Comparison of MATTC and LASTRAC CF n-factor growth curves for the NLF-0416 (left), N1 (center) and D0 (right) airfoils for a Reynolds number of 20 million and a sweep angle of 20 degrees. The top row shows the upper surface and the bottom row shows the lower surface results. 

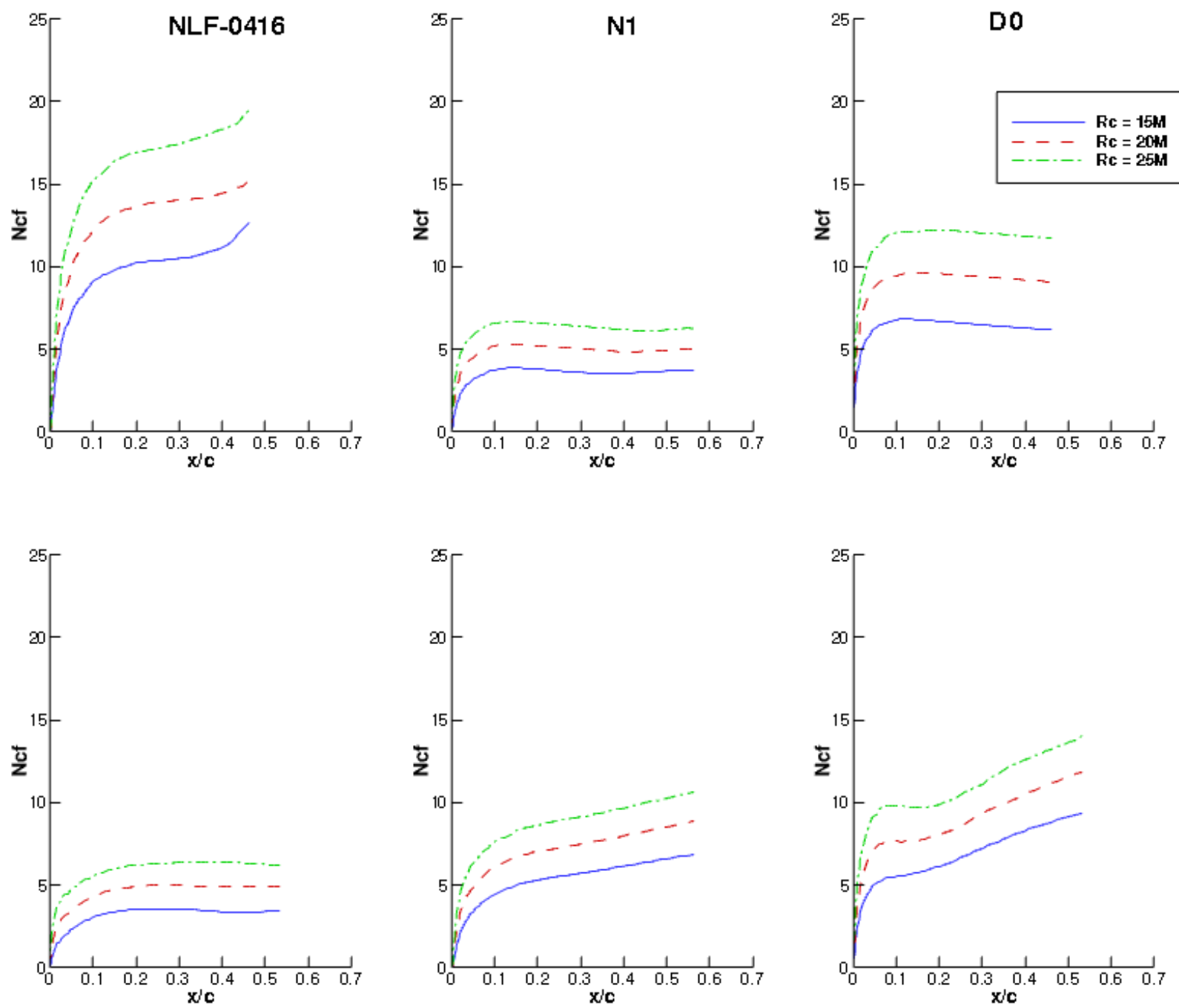

Figure 7 - Effect of Reynolds number on LASTRAC CF n-factor growth curves for the NLF-0416 (left), N1 (center) and D0 (right) airfoils at a sweep angle of 20 degrees. The top row shows the upper surface and the bottom row shows the lower surface. 

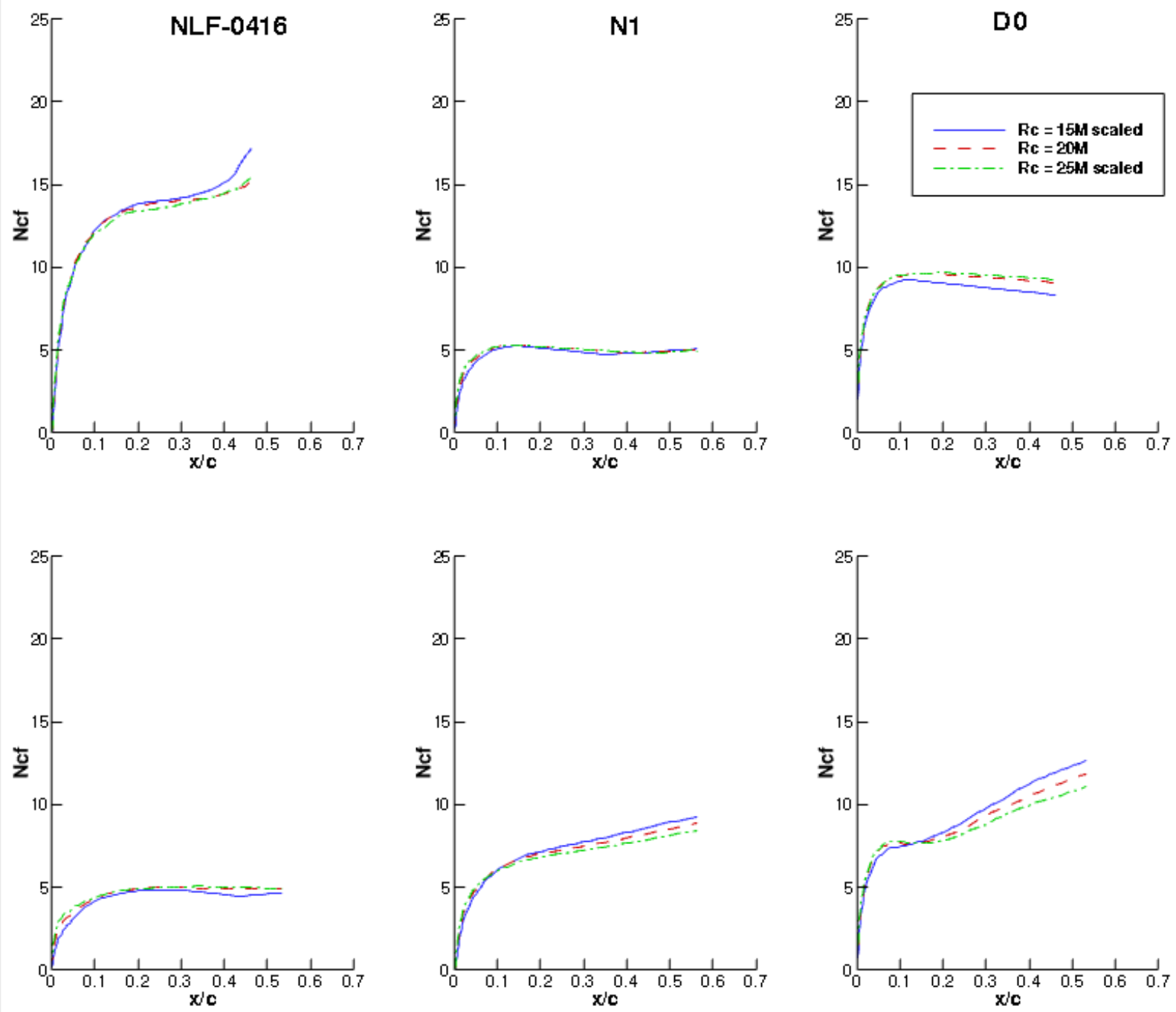

Figure 8 - Effect of MATTC Reynolds number scaling function on LASTRAC CF n-factor growth curves for the NLF-0416 (left), N1 (center) and D0 (right) airfoils at a sweep angle of 20 degrees. The top row shows the upper surface and the bottom row shows the lower surface. 

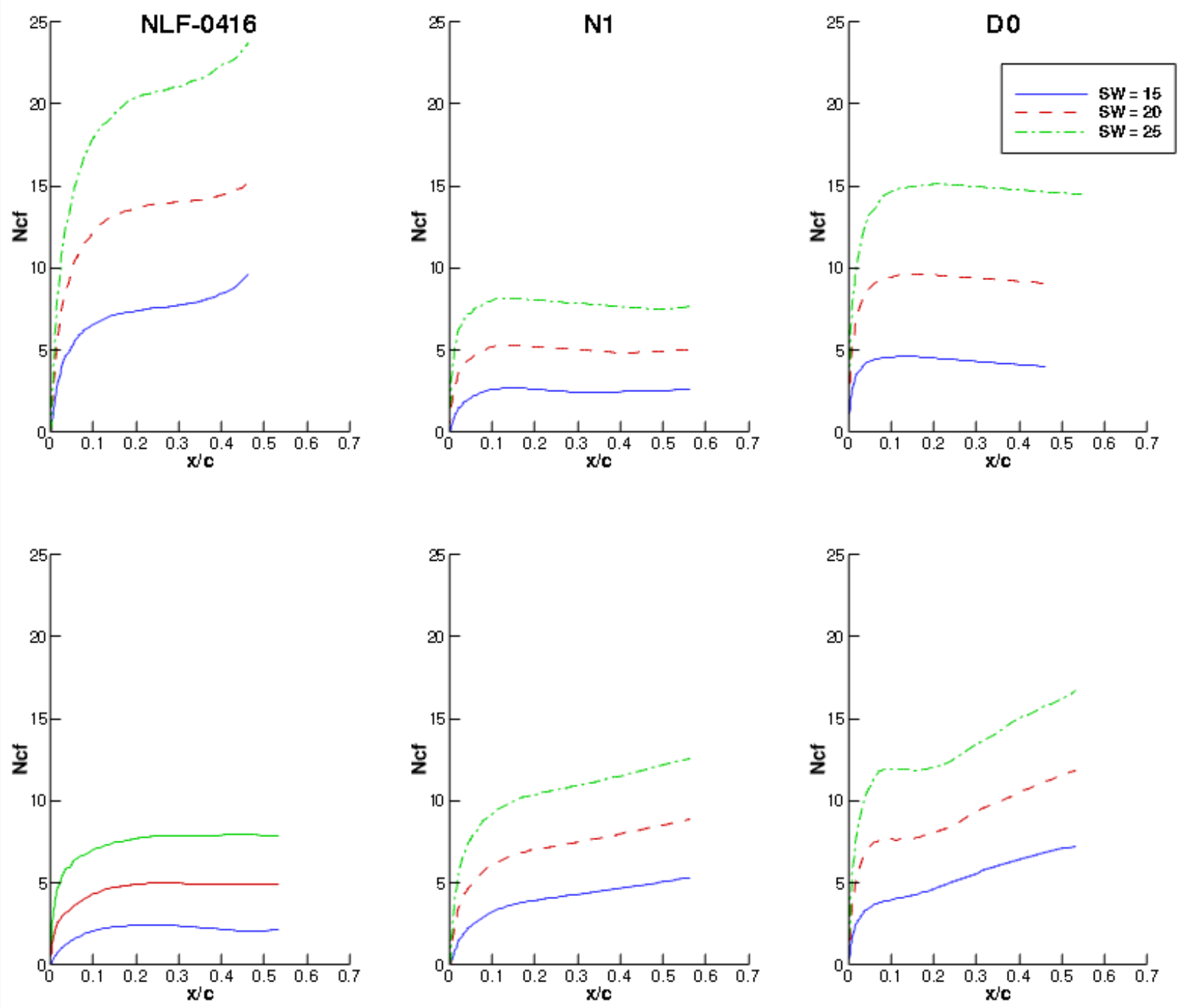

Figure 9 - Effect of sweep angle on LASTRAC CF n-factor growth curves for the NLF-0416 (left), N1 (center) and D0 (right) airfoils at a Reynolds number of 20 million. The top row shows the upper surface and the bottom row shows the lower surface. 

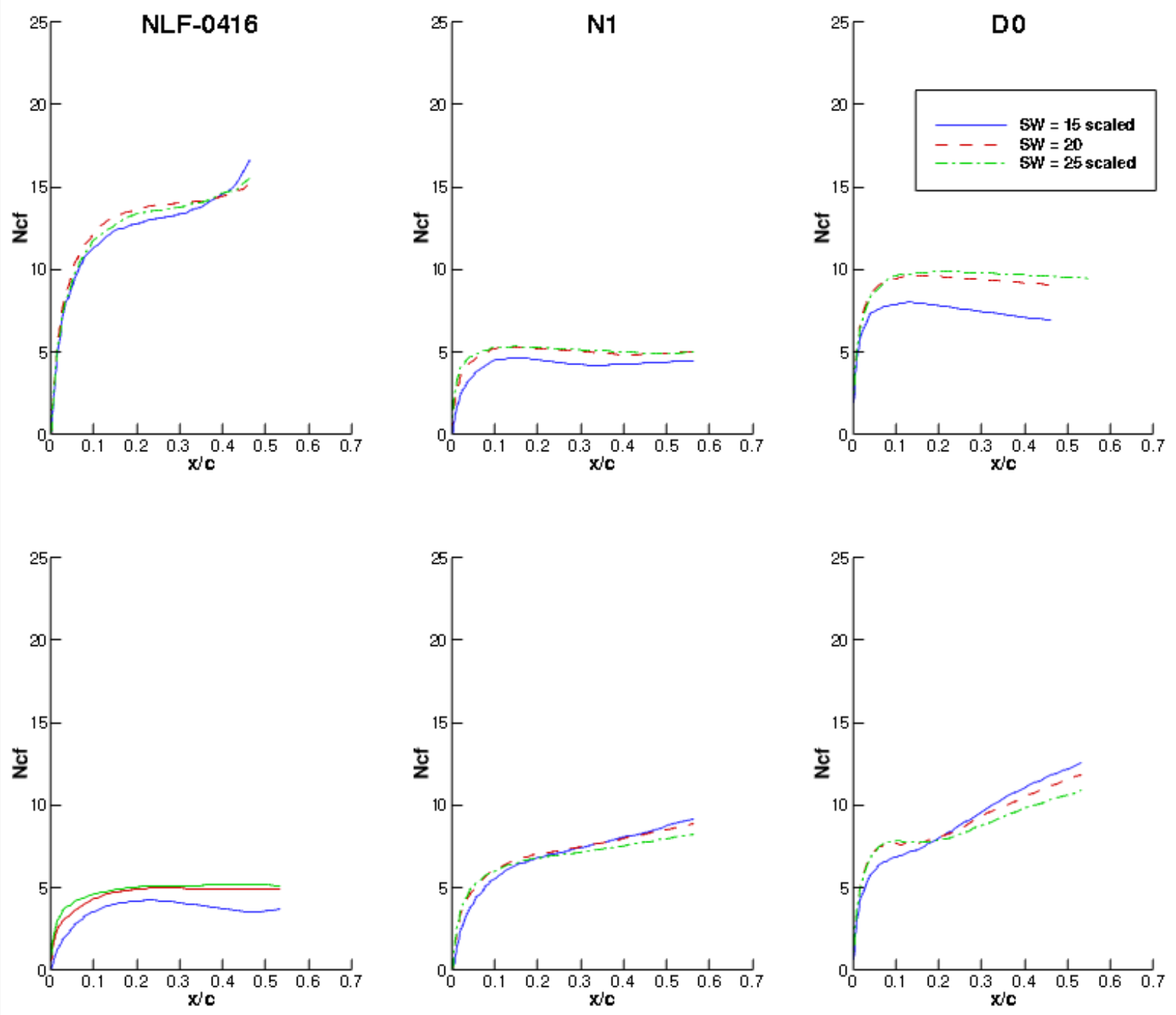

Figure 10 - Effect of MATTC sweep scaling function on LASTRAC CF n-factor growth curves for the NLF-0416 (left), N1 (center) and D0 (right) airfoils at a Reynolds number of 20 million. The top row shows the upper surface and the bottom row shows the lower surface. 

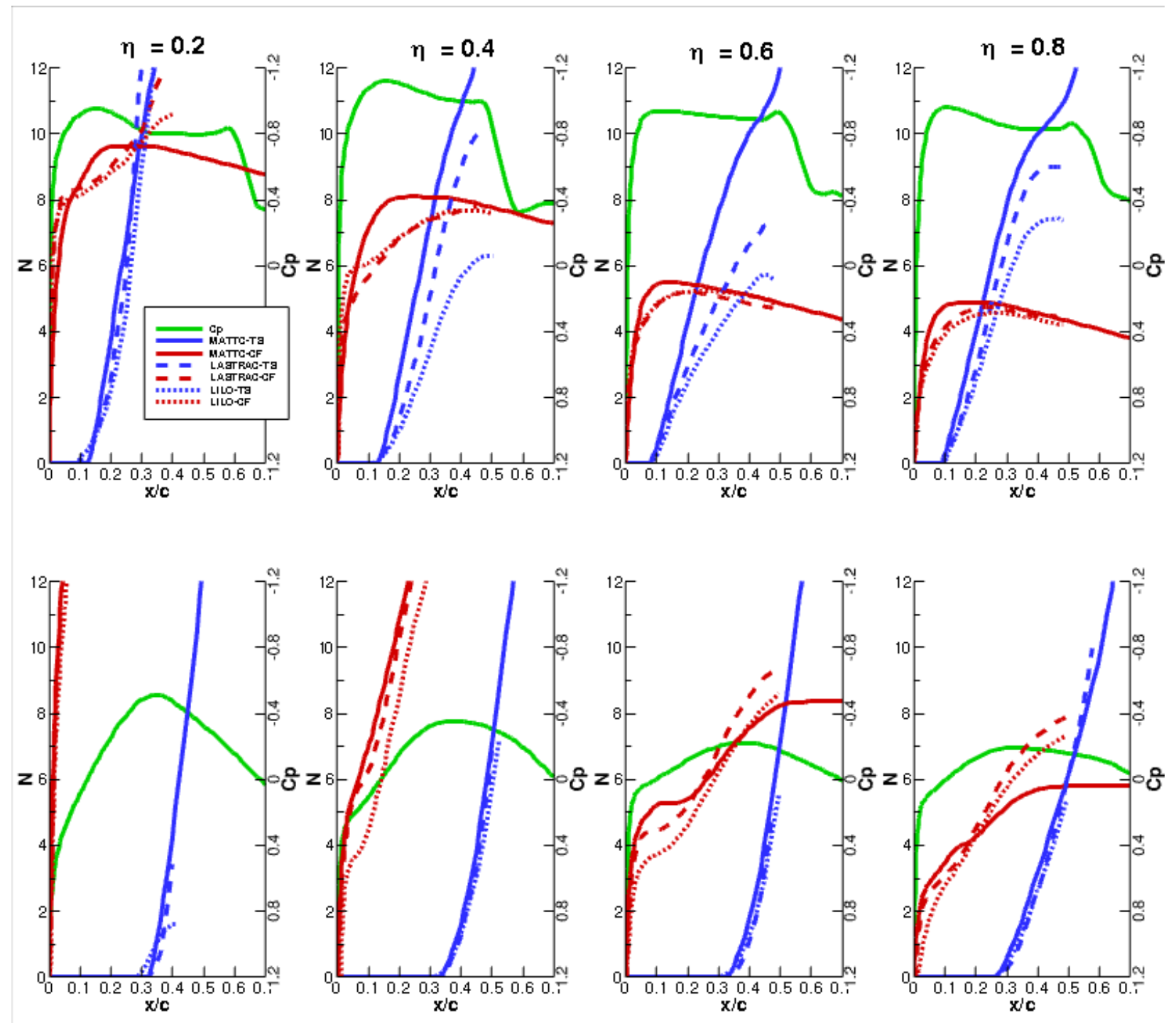

Figure 11 - Pressure distributions and n-factor growth curves for the NTF NLF wind tunnel model computed using the MATTC (solid line), LASTRAC (dashed line) and LILO (dotted line) codes. Columns are for (left to right) wing semi-span stations eta $=0.2,0.4,0.6$ and 0.8 , with upper surface values in the top row and lower surface values in the bottom row. TS growth curves are shown in blue, CF in red and the pressure distribution in green. 


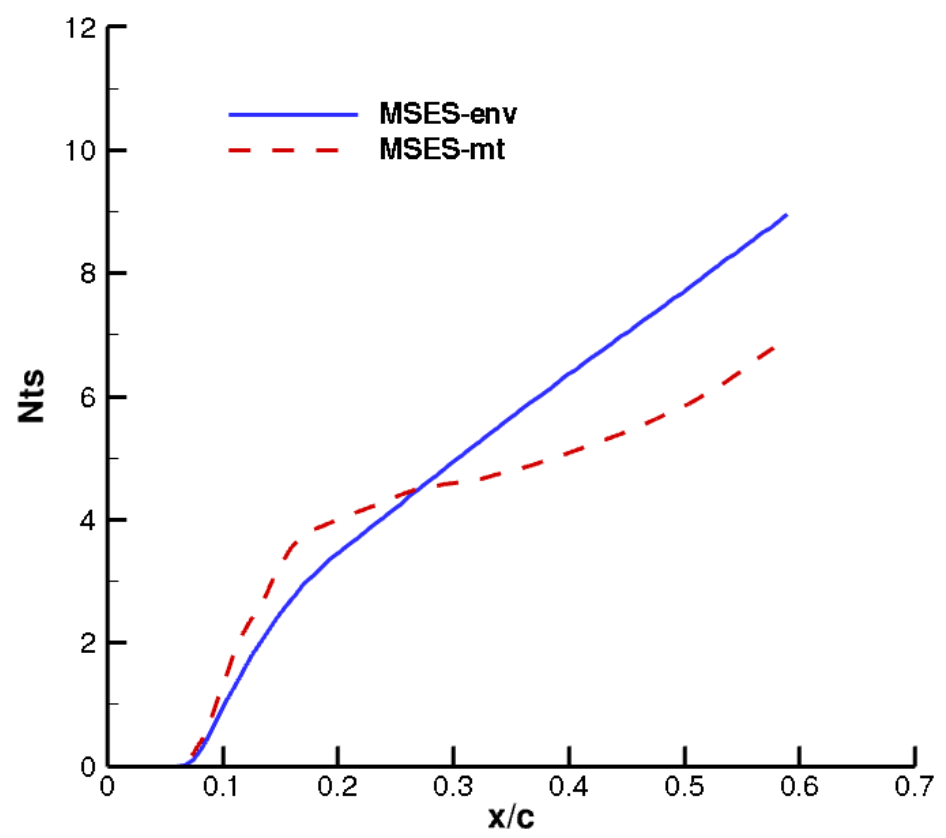

a) $\mathrm{cl}=0.7$

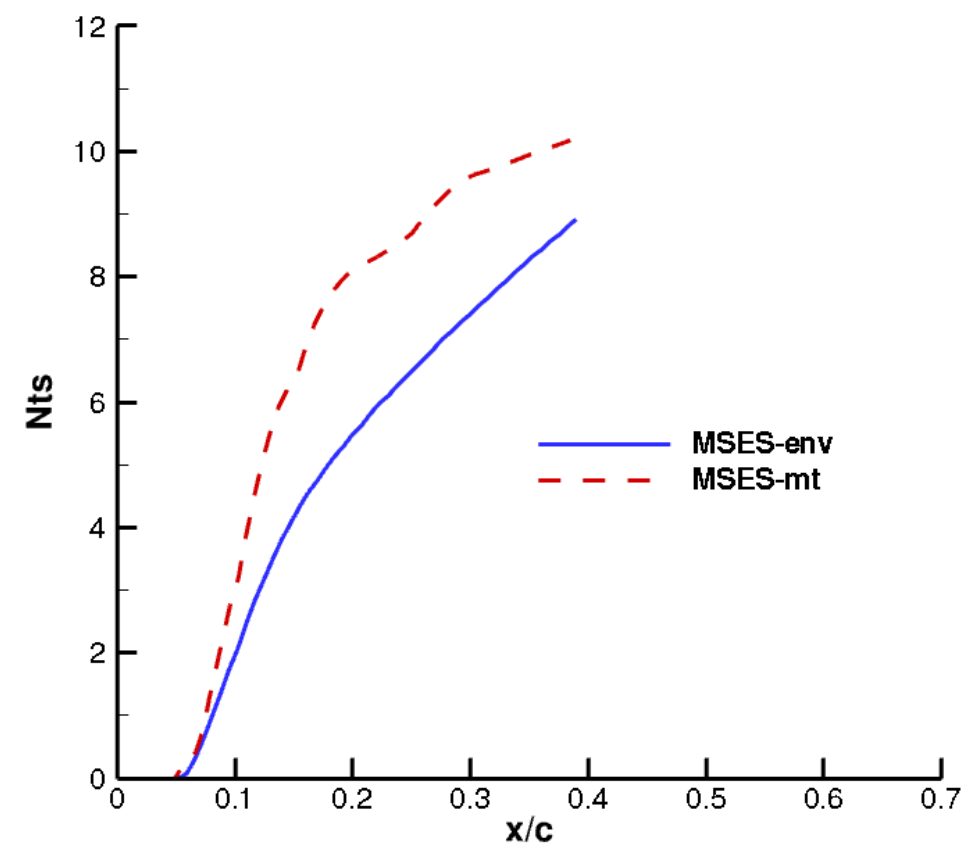

b) $\mathrm{cl}=0.8$

Figure 12 - MSES results for the N1 airfoil at Rn=12 million using the envelope (MSES-env) and mode tracking (MSES-mt) methods. 


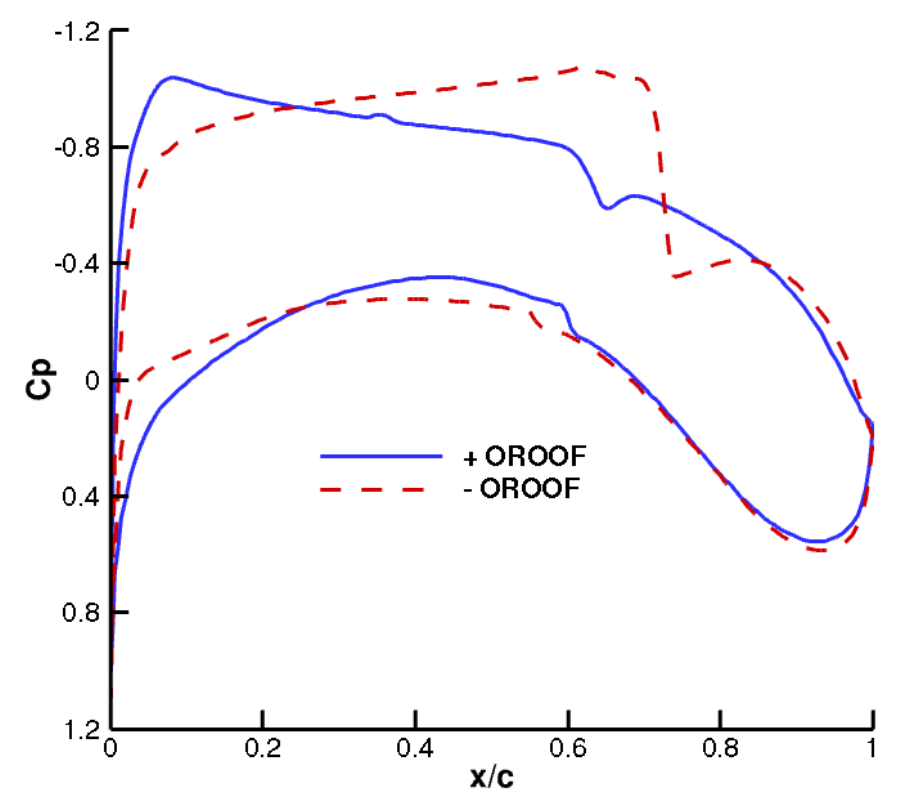

a) Pressure distributions

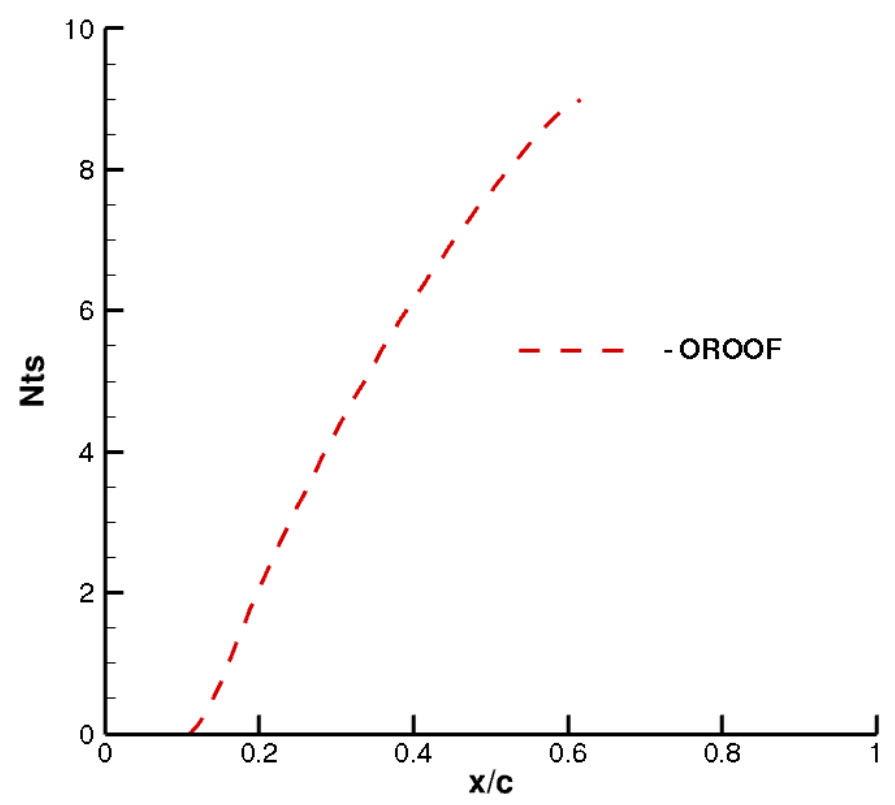

b) TS n-factor growth curve from MSES

Figure 13 - Design results using the OROOF constraint in CDISC with MSES. The blue line (+OROOF) is for turbulent design for low wave drag and the red line (-OROOF) is for an NLF design with a specified transition location of $\mathrm{x} / \mathrm{c}=0.60$ on the upper surface. 


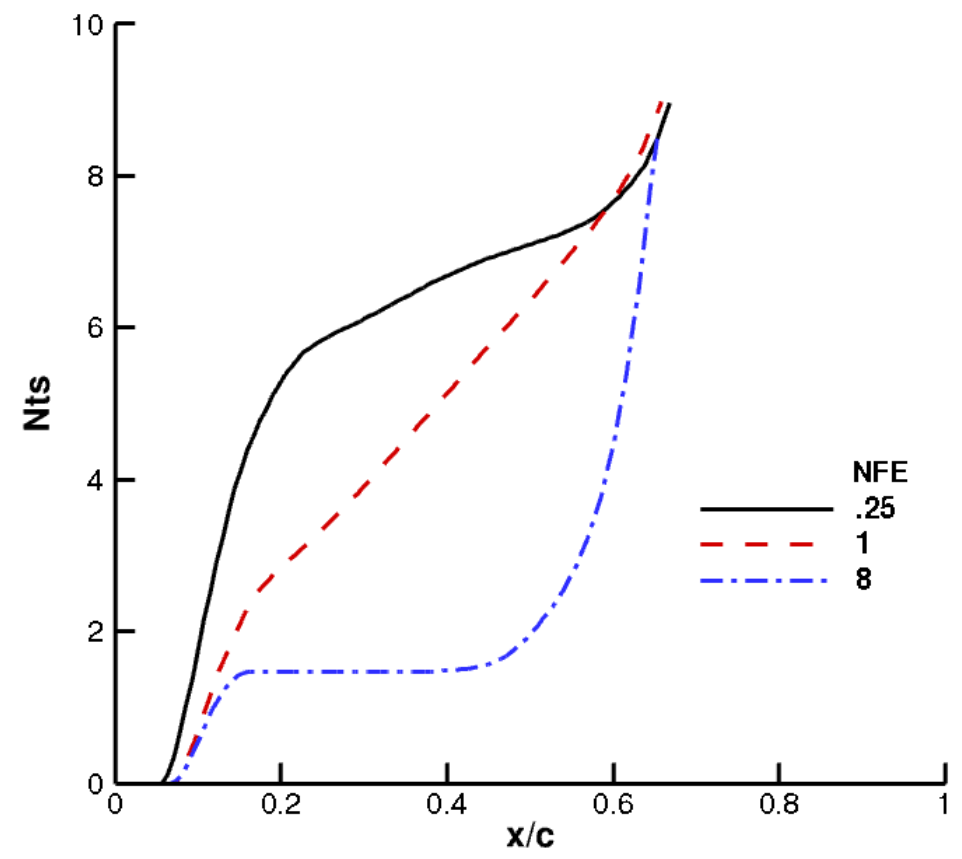

a) TS n-factor growth curves from MSES

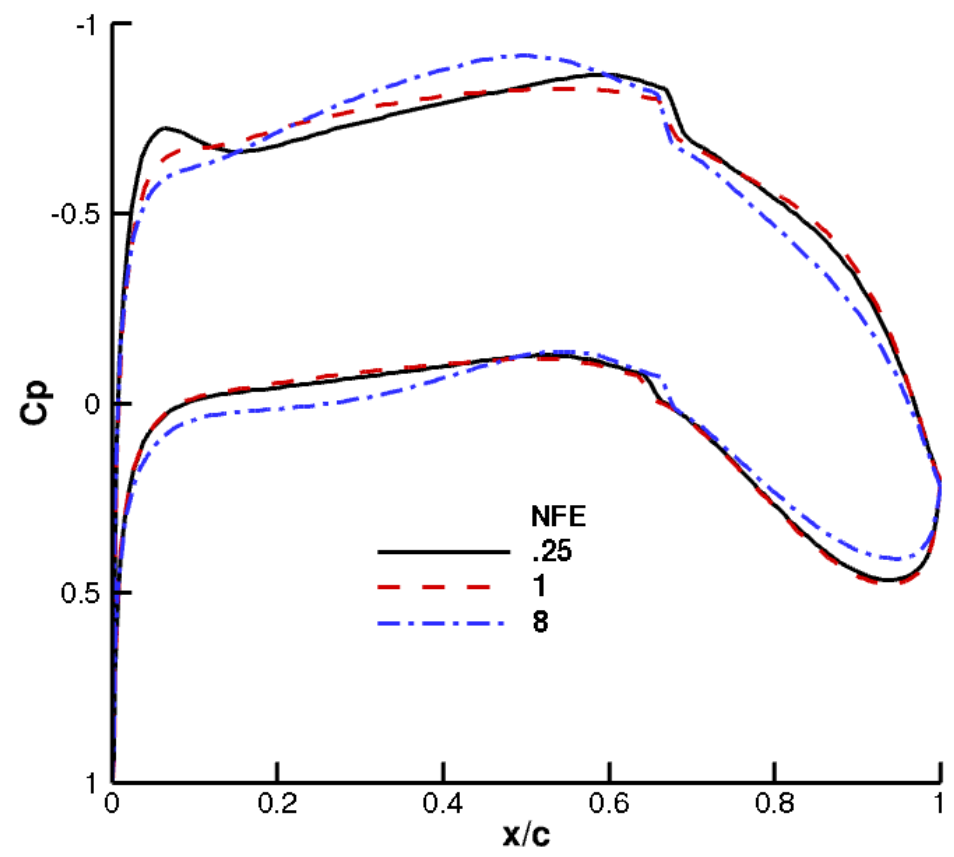

b) Pressure distributions

Figure 14 - Effect of varying the n-factor exponent (NFE) in the NLFCP constraint in CDISC. 


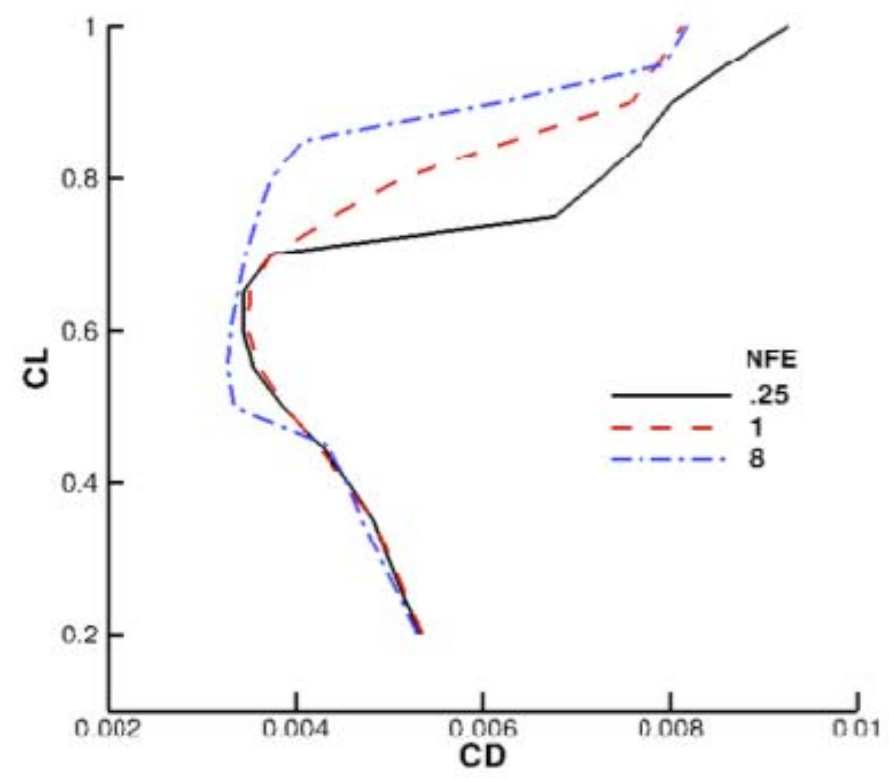

c) Drag polar

Figure 14 (concluded) - Effect of varying the n-factor exponent (NFE) in the NLFCP constraint in CDISC.

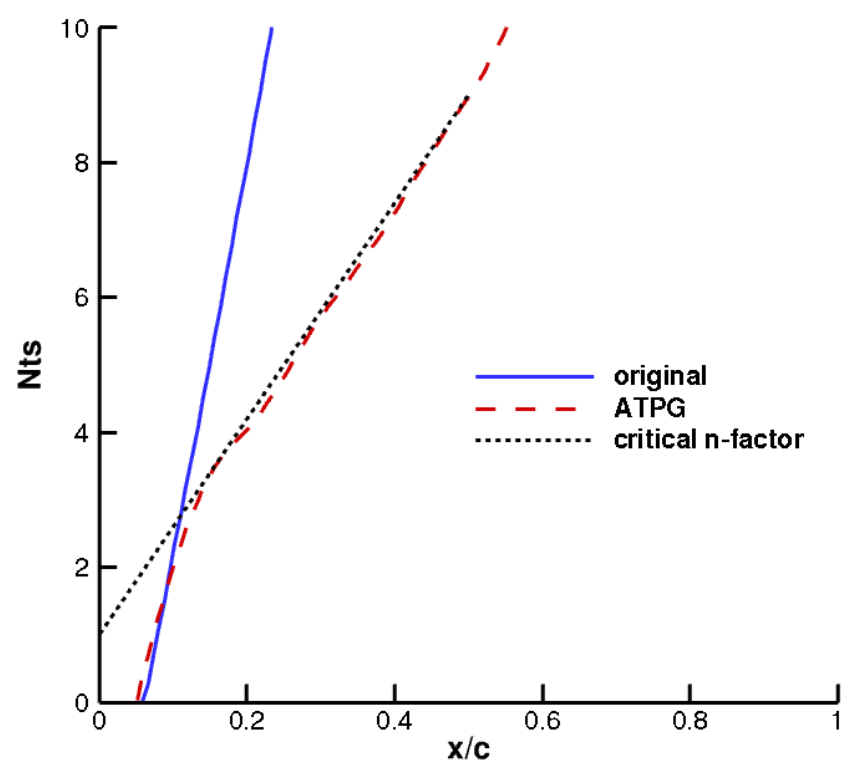

Figure 15 - Illustration of the variable critical n-factor limit. 


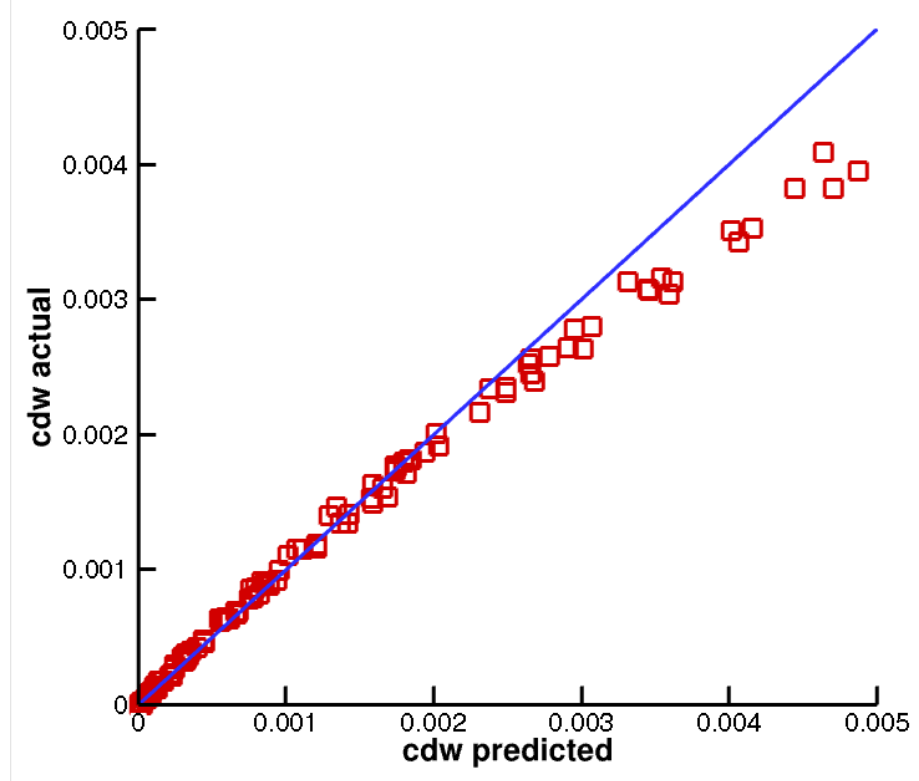

a) Calibration using NACA 4-digit airfoils

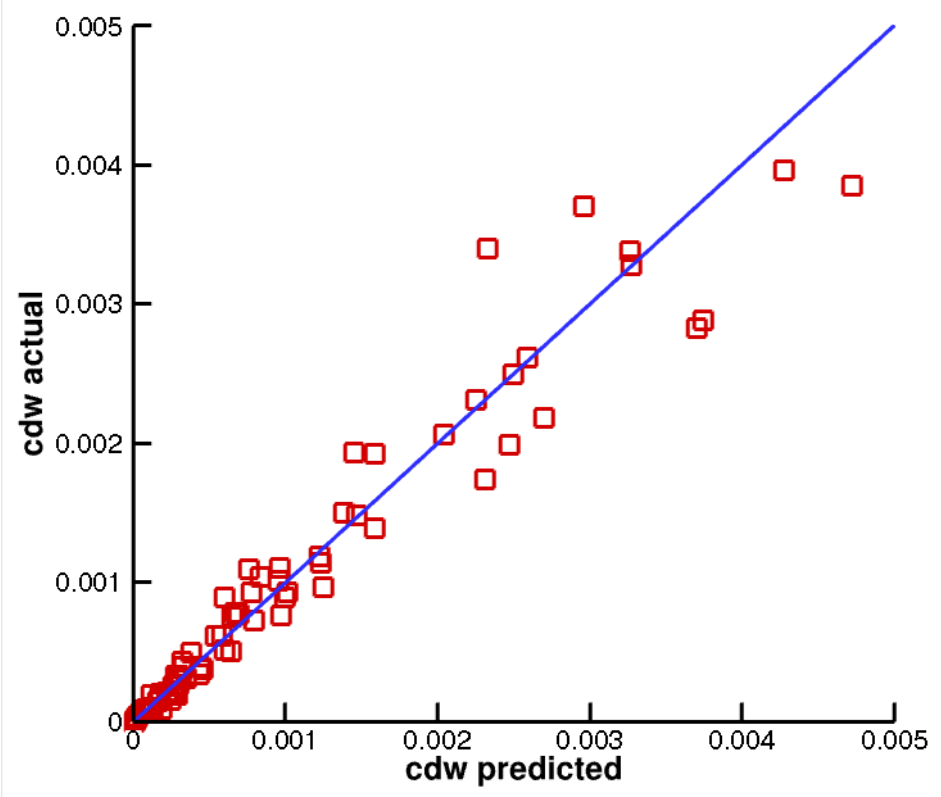

b) Evaluation using supercritical airfoils

Figure 16 - Development of ATPG equation for estimation of wave drag. 


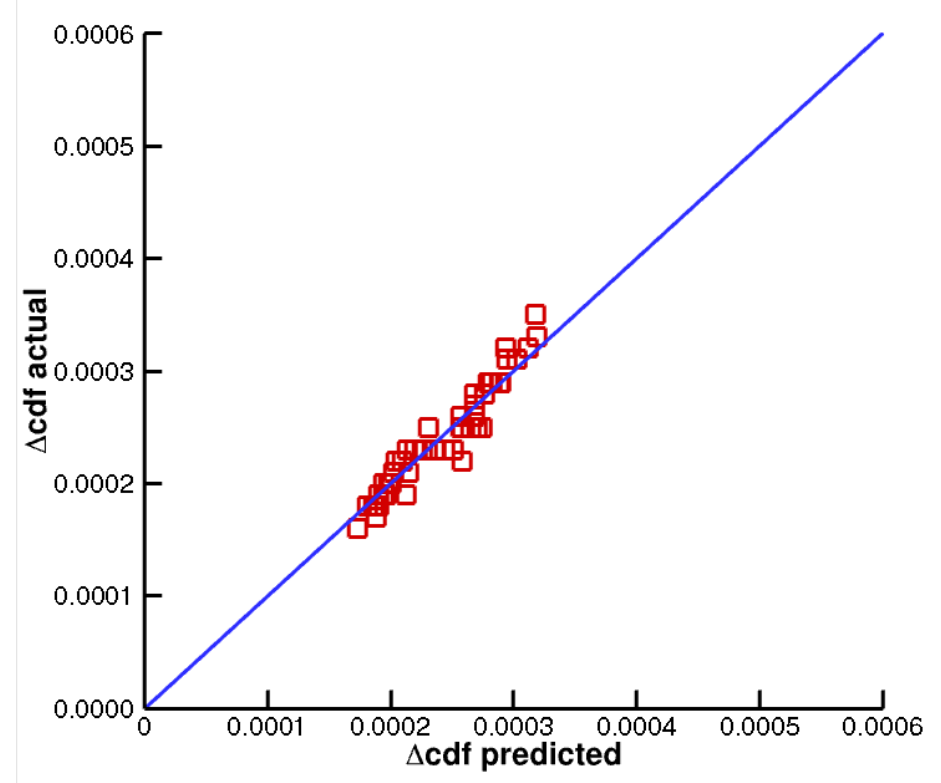

a) Skin-friction drag

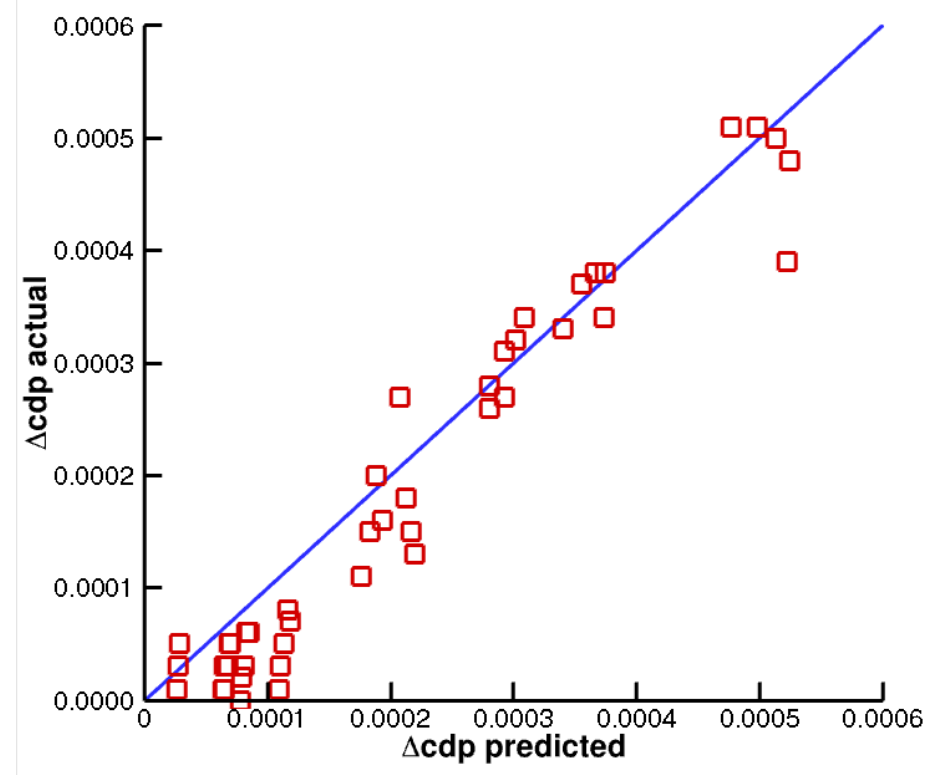

b) Pressure drag

Figure 17 - Development of ATPG equation for estimation of skin-friction and pressure drag components. The $\Delta$ refers to change in drag coefficient for a change in extent of laminar flow of $d(x / c)=0.1$. 


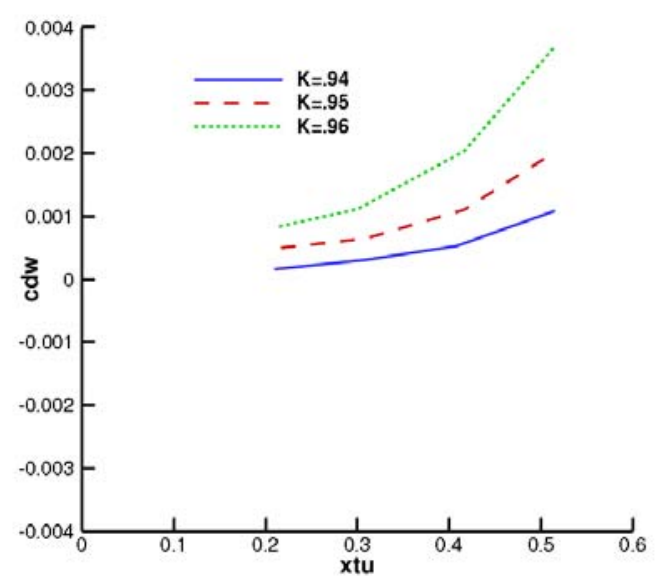

a) Wave drag

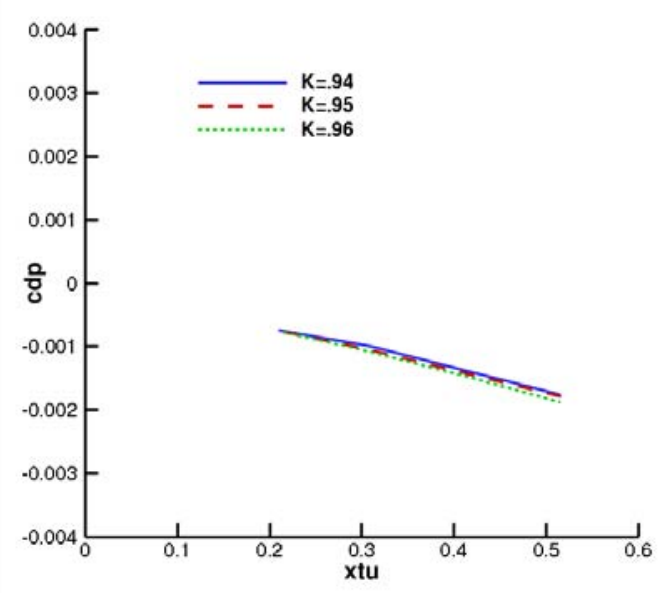

c) Pressure drag

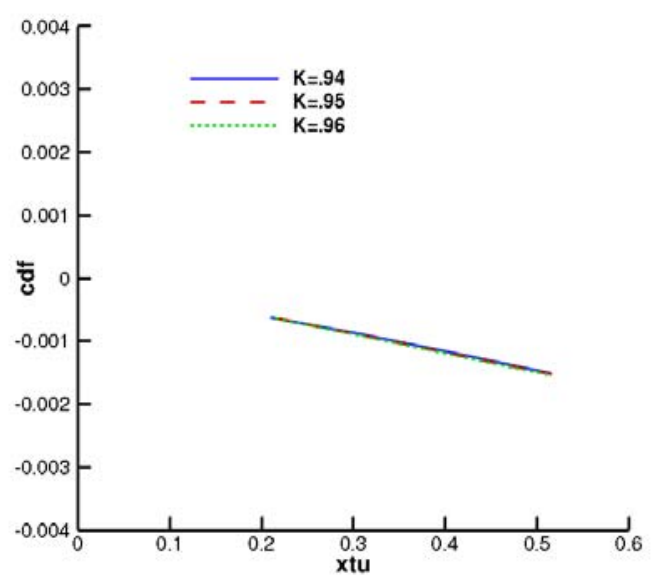

b) Skin-friction drag

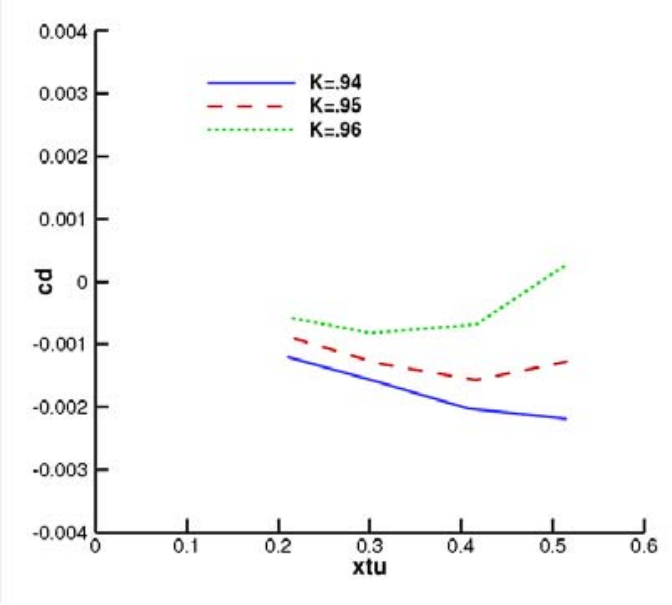

d) Total drag

Figure 18 - ATPG-based drag results for airfoil designs with varying values of the Korn parameter (K) and upper surface transition locations (xtu). 


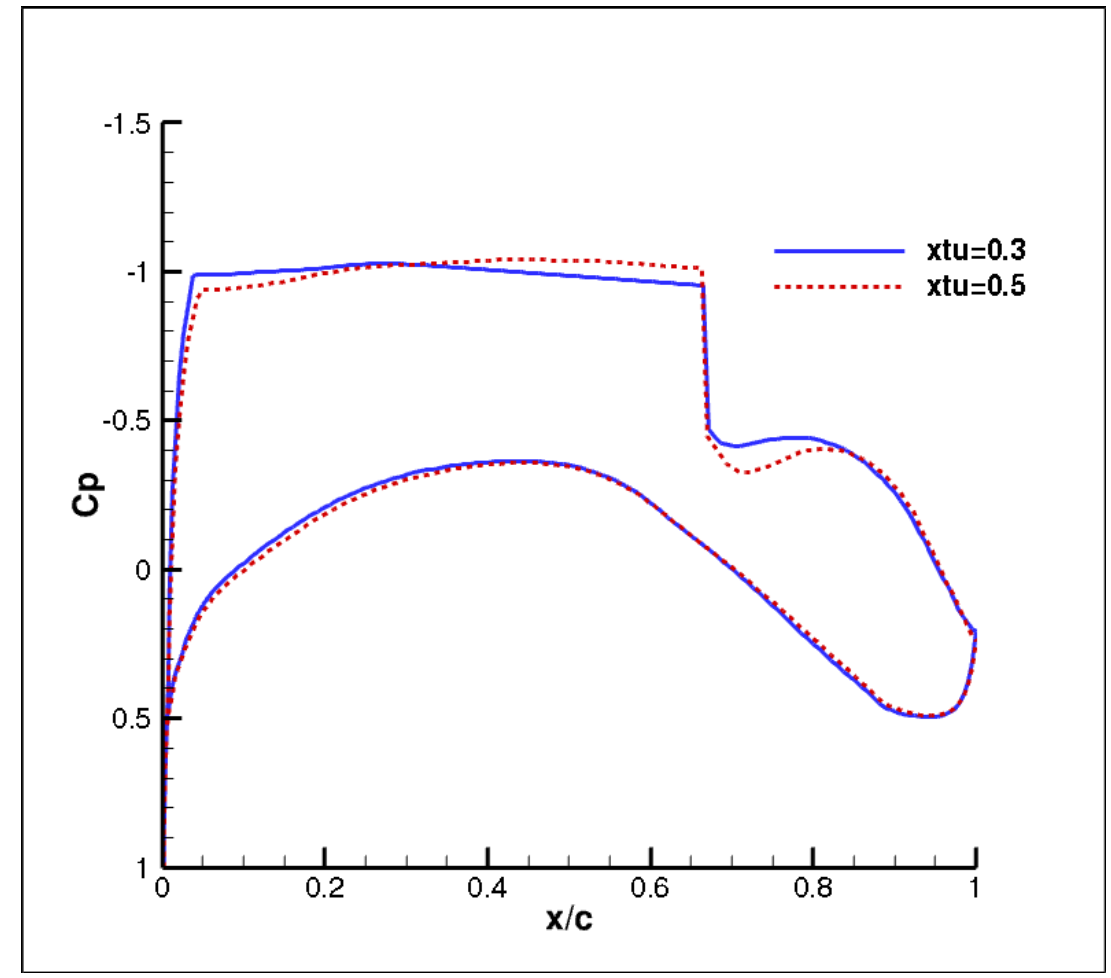

Figure 19 - Target pressures for ATPG $\mathrm{K}=0.96$ designs having optimum (xtu=0.3) and maximum (xtu=0.5) upper surface transition locations.

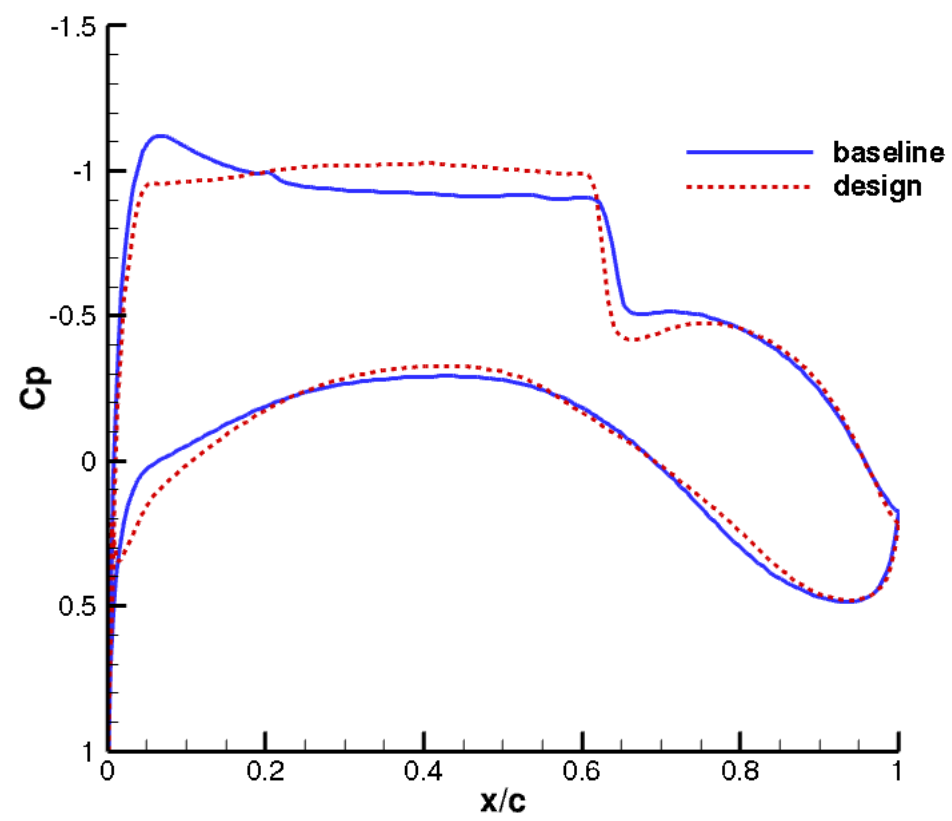

Figure 20 - Pressure distributions for baseline (D0) and ATPG K=0.95 design having optimum (xtu=0.4) upper surface transition location. 


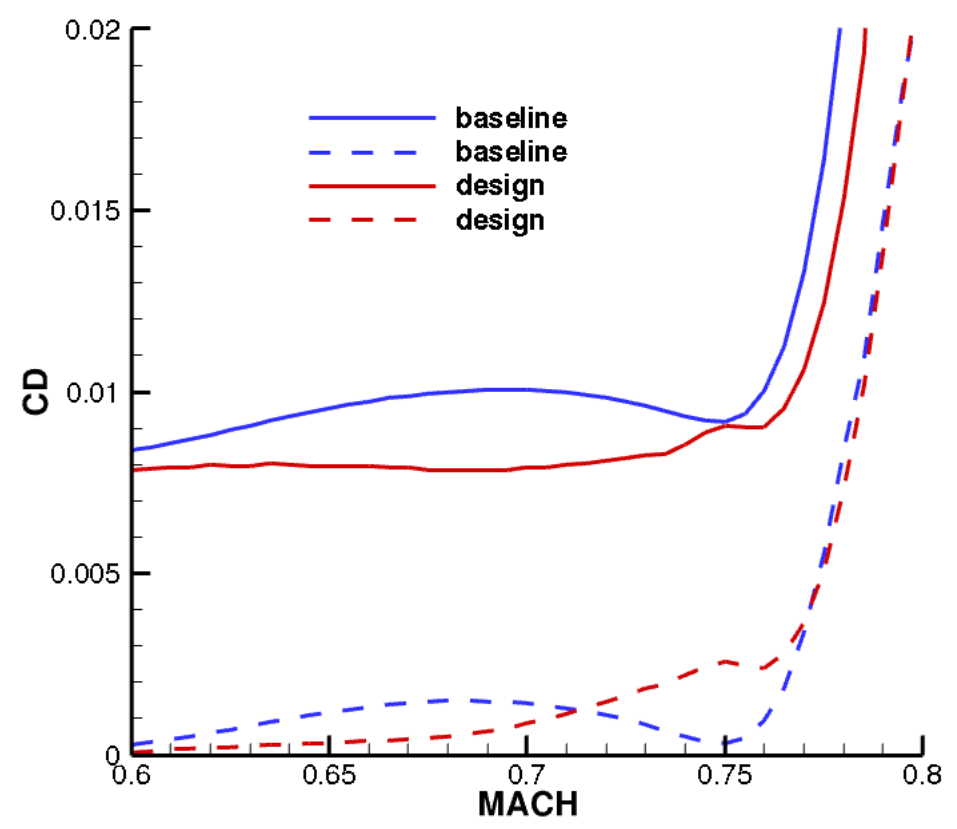

a) Drag rise

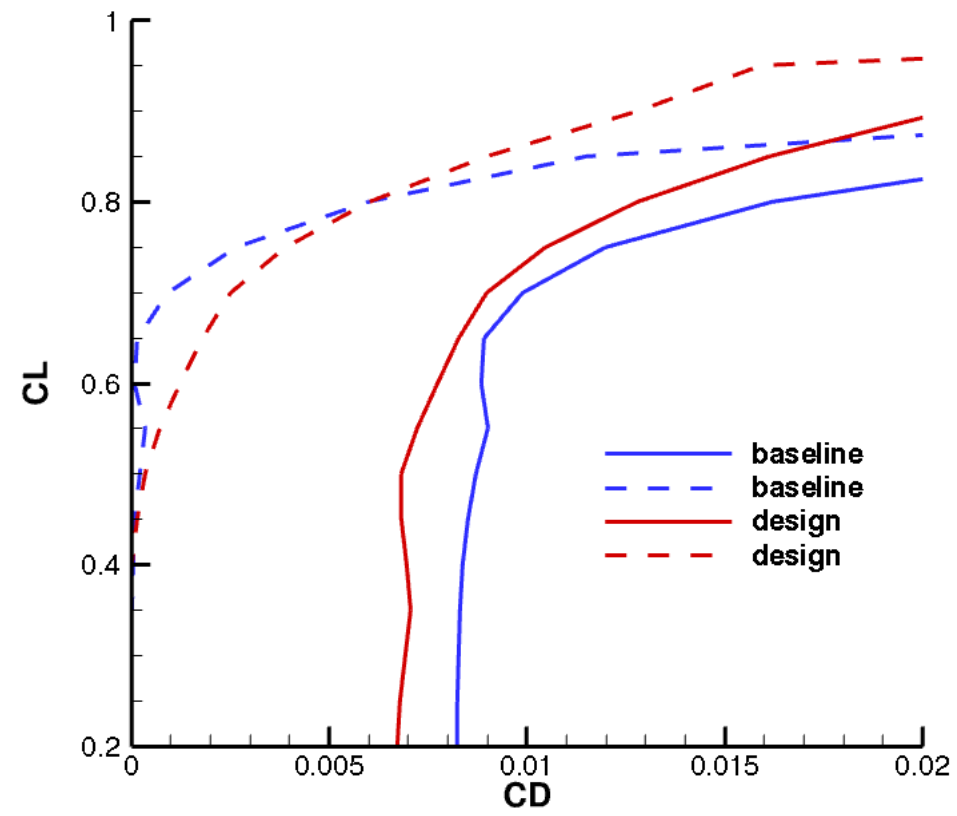

b) Drag polar

Figure 21 - Drag rise and drag polar curves for baseline (D0) and ATPG k=0.95 design with xtu=0.4. Solid lines are for total drag, dashed lines are for wave drag. 